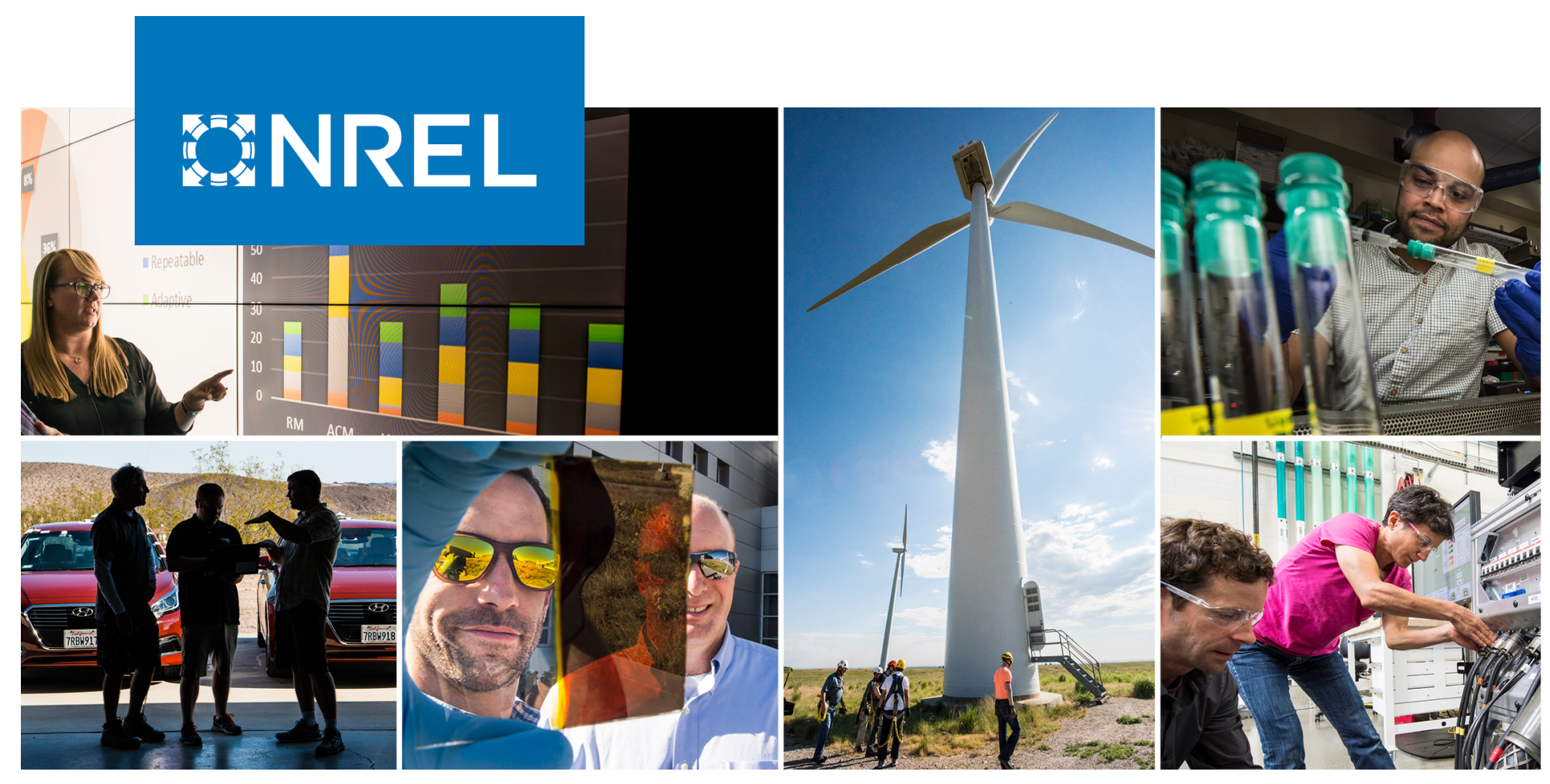

\title{
Evaluating Utility-Scale PV-Battery Hybrids in Operational Models for the Bulk Power System
}

Venkat Durvasulu, Caitlin Murphy, and Paul Denholm

National Renewable Energy Laboratory

NREL is a national laboratory of the U.S. Department of Energy Office of Energy Efficiency \& Renewable Energy

Operated by the Alliance for Sustainable Energy, LLC

This report is available at no cost from the National Renewable Energy Laboratory (NREL) at www.nrel.gov/publications.
Technical Report

NREL/TP-6A20-78850

April 2021 


\section{GNREL}

\section{Evaluating Utility-Scale PV-Battery Hybrids in Operational Models for the Bulk Power System}

Venkat Durvasulu, Caitlin Murphy, and Paul Denholm

National Renewable Energy Laboratory

\section{Suggested Citation}

Durvasulu, Venkat, Caitlin Murphy, and Paul Denholm. 2021. Evaluating Utility-Scale PVBattery Hybrid in Operational Models for the Bulk Power System. Golden, CO: National Renewable Energy Laboratory. NREL/TP-6A20-78850.

https://www.nrel.gov/docs/fy21osti/78850.pdf.

NREL is a national laboratory of the U.S. Department of Energy Office of Energy Efficiency \& Renewable Energy Operated by the Alliance for Sustainable Energy, LLC

This report is available at no cost from the National Renewable Energy Laboratory (NREL) at www.nrel.gov/publications.

Contract No. DE-AC36-08GO28308
Technical Report

NREL/TP-6A20-78850

April 2021

National Renewable Energy Laboratory 15013 Denver West Parkway Golden, CO 80401

303-275-3000 • www.nrel.gov 


\section{NOTICE}

This work was authored by the National Renewable Energy Laboratory, operated by Alliance for Sustainable Energy, LLC, for the U.S. Department of Energy (DOE) under Contract No. DE-AC36-08GO28308. Funding provided by the U.S. Department of Energy Office of Energy Efficiency and Renewable Energy Solar Energy Technologies Office and the Office of Strategic Analysis. The views expressed herein do not necessarily represent the views of the DOE or the U.S. Government.

This report is available at no cost from the National Renewable Energy Laboratory (NREL) at www.nrel.gov/publications.

U.S. Department of Energy (DOE) reports produced after 1991 and a growing number of pre-1991 documents are available free via www.OSTI.gov.

Cover Photos by Dennis Schroeder: (clockwise, left to right) NREL 51934, NREL 45897, NREL 42160, NREL 45891, NREL 48097, NREL 46526.

NREL prints on paper that contains recycled content. 


\section{Acknowledgments}

We express our appreciation to the following colleagues at the National Renewable Energy Laboratory for their feedback and suggestions on this work: Patrick Brown, Kelly Eurek, Anna Schleifer, and Jaquelin Cochran. Editing was provided by Mike Meshek and Madeline

Schroeder. We thank LADWP for allowing the use of data sets generated for the LA100 study. 


\section{List of Acronyms}

AC

BES

CSP-TES

DC

GWh

ILR

LADWP

MWh

PCM

PV

SAM

SoC

TES

TWh alternating current

battery energy storage

concentrating solar power with thermal energy storage

direct current

gigawatt-hour

inverter loading ratio

Los Angeles Department of Water and Power

megawatt-hour

production cost model

photovoltaic

System Advisor Model

state of charge

thermal energy storage

terawatt-hour 


\section{Abstract}

Systems that combine solar photovoltaic and battery energy storage technologies (PV-BES) are increasingly being proposed for, and deployed on, the bulk power system. The operation and value of PV-BES systems have been extensively studied from the perspective of project developers through analyses that maximize plant-level revenue. However, PV-BES hybrids' operational characteristics have seldom been studied from the perspective of bulk power system operators, who seek to optimize the performance of a suite of generation and storage assets that are connected via the transmission network.

This work presents modeling approaches for representing and evaluating PV-BES hybrids in a model that optimizes operations across the bulk power system. Its novel contributions include demonstrating a technique to modify a unit commitment and dispatch model to represent the operational synergies of PV-BES hybrids. In particular, we describe the challenges of, and an approach for, representing so-called DC-coupled PV-BES - which use a single bidirectional inverter - as a dispatchable resource in a commercial, production cost model (PCM), namely PLEXOS.

We demonstrate this technique in a PCM study of the Los Angeles Department of Water and Power test system, by replacing existing PV and battery generators on the test system with our PV-BES hybrids. We then pursue scenario analysis designed to isolate the various drivers of operational strategies for DC-coupled PV-BES hybrids, including the nature of coupling, PV penetration on the system, and varying inverter loading ratios (or degrees of over-sizing the PV field). Results from the analysis include utilization profiles for the PV DC energy across available pathways, dispatch profiles for the battery component, and the hybrid technologies' impacts on system-wide production costs. The approach we present can be used in any PCM study of PV-BES hybrids as a resource in different power system configurations and services. 


\section{Table of Contents}

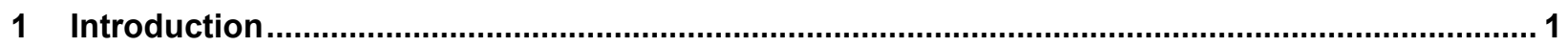

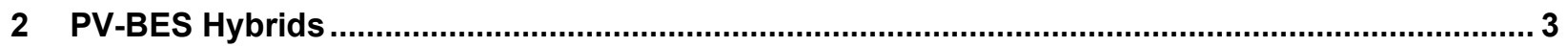

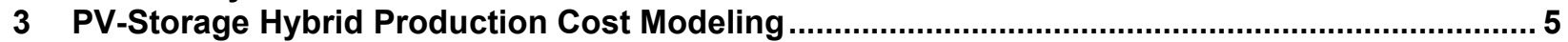

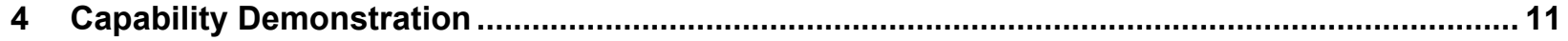

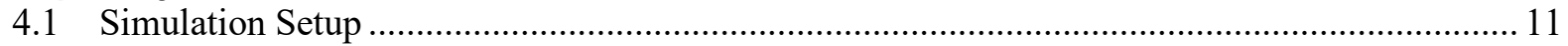

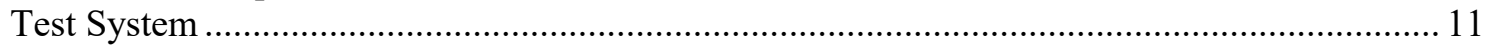

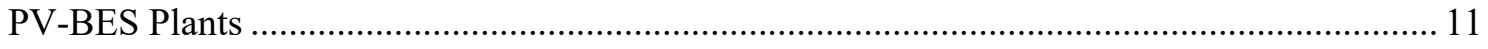

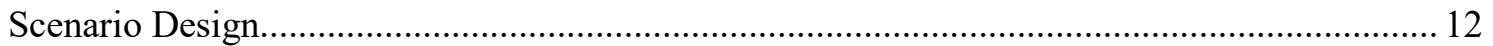

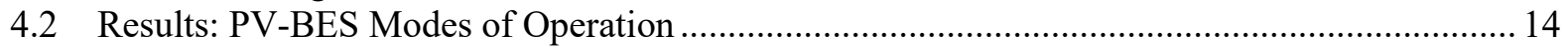

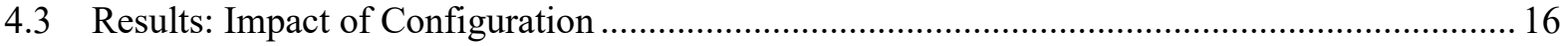

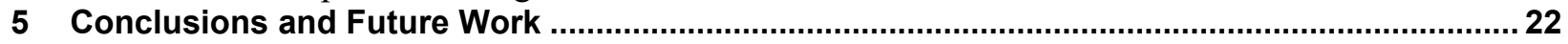

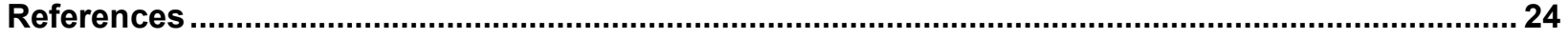

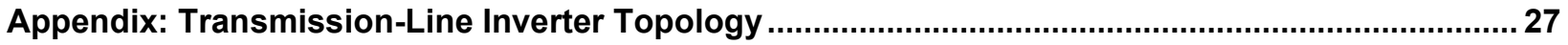




\section{List of Figures}

Figure 1. PV-BES hybrid configurations, including (a) an AC-coupled system with inverter communication link and (b) a DC-coupled system with grid charging capabilities using a bidirectional inverter.

Figure 2. Simulation components that a PV-BES object must represent, along with their efficiencies and ratings for PCM analysis.

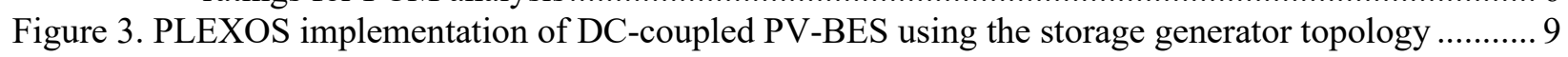

Figure 4. Hourly operation of DC-coupled PV-BES Plant 3 with ILR=2.0 on July 12 and $13 \ldots \ldots \ldots \ldots \ldots . . .15$

Figure 5. Hourly operation of DC-coupled PV-BES Plant 3 in ILR 1.3 on July 11, 2020 in the 1/2 PV Scenario (left) and ILR $=1.3$ scenarios

Figure 6. Battery discharge behavior for the battery component of the DC-coupled PV-BES hybrids with ILR 1.3 (pink) and 2.0 (green), aggregated over the 1-year analysis period....

Figure 7. Destination of PV DC energy collected as a function of ILR for all DC-coupled PV-BES hybrids in this demonstration.

Figure 8. The distribution of the unutilized PV DC energy due to losses and spillage ....

Figure A-1. PLEXOS implementation of DC-coupled PV-BES using a transmission lineinverter topology

\section{List of Tables}

Table 1. Equations and Values that Define the Efficiencies for Each Available Pathway ...... 11

Table 2. Capacity Inputs and Generation Outputs for all Generators in the LADWP System 12

Table 3. Details of the DC-Coupled PV-BES Implemented in the Base Case LADWP System 13

Table 5. Utilization Metrics for the DC-Coupled Hybrid-Inverter 18 


\section{Introduction}

Solar photovoltaic (PV) systems have experienced rapid and widespread deployment on the U.S. bulk power system in recent years, and their deployment is expected to continue and accelerate. Also, interest in, and deployment of, battery energy storage (BES) is growing (Cole et al. 2020; EIA 2020), in part to mitigate the declining operational value of PV systems with increasing penetration (Wiser et al. 2017; Mills and Wiser 2012; Hirth 2015; 2013; Mai, Cole, and Reimers 2019)

While BES systems can be deployed independently, recent installations and interconnection queue data indicate growing industry interest in systems that couple PV and BES through colocation and perhaps coordinated operations (Wiser et al. 2020). Moreover, market projections indicate an acceleration in the deployment of coupled PV-BES systems in the United States (Hledik et al. 2019). These trends reflect both policy drivers (e.g., the federal investment tax credit can be applied to storage if it charges primarily from colocated PV) and the potential for technology synergies (Gorman et al. 2020).

It is important to determine the actual value of colocated or coupled systems, particularly relative to independent deployments and also given the number of options for configurations and component sizing. Common approaches for quantifying the operational value of generation assets include price-taker methods and production cost models (PCMs) (Martinek et al. 2018). The respective merits of PCM and price-taker methods are well established, as are the requirements for performing simulation and analysis (Martinek et al. 2018).

The price-taker approach is one of the most commonly implemented techniques to estimate the potential revenue of a single installation, based on historical or forecasted electricity prices in a region (DiOrio, Denholm, and Hobbs 2020; Martinek et al. 2018; Gorman et al. 2020; Schleifer et al. 2021). Given their computational efficiency, price-taker methods can be used to study how the value of PV-BES systems depends on the complex characteristics of the battery component. For example, recent research has explored how PV-BES value varies when using different battery dispatch algorithms (Gorman et al. 2020; Mills and Rodriguez 2020), or the when considering the impact of nonlinear aspects of battery systems (e.g., voltage, current, and cycle degradation) (DiOrio, Denholm, and Hobbs 2020).

Price-taker methods are useful for exploring how these characteristics influence the value that can be realized through PV-BES operational synergies, particularly for installations that are too small to induce changes in system marginal prices. However, they do not capture the impact of new resources on the rest of the system. In addition, price-taker methods are typically configured to maximize plant-level revenues, as opposed to system-level benefits.

To understand the value of various resources at the system level, a PCM is typically used. PCMs optimize the operation of a new resource along with all the existing generators to minimize the total system variable operating (production) cost. The benefits of a new resource are then measured in terms of a reduction in production cost relative to an alternative mix of resources that does not include the added generator (Jorgenson et al. 2018). PCMs are in important tool used by utilities and other power system planners to develop and analyze resource plans. Because of the potential role of PV-BES hybrids in the evolving power system, and because of 
the unique characteristics of certain PV-BES configuration, it is important to accurately characterize these technologies in commercially available PCM tools.

Commercial PCMs can model PV and storage with various levels of detail. However, in our experience, many commercial PCM software packages do not have a preprogrammed simulation object that captures all the nuances of the emerging PV-BES technologies, particularly those associated with DC-coupled systems.

This study focuses on the development of a generalized modeling approach for representing PVBES in PCMs, using a specific commercial tool as an example. Section 2 provides a summary of utility-scale PV-BES, including all its essential components and relevant nuances (compared to independent PV and battery systems). Section 3 describes a generalized approach to modeling PV-BES hybrids in a commercial PCM software, and its specific implementation in the PLEXOS model. Section 4 applies this approach in a model based on the Los Angeles Department of Water and Power (LADWP) test system. We demonstrate its ability to capture differences between hybrid and conventional (noncoupled) PV and BES configuration. In Section 5, we present conclusions and discuss further applications and refinements that would advance the current understanding of PV-BES impacts and value on the bulk power system. The appendix describes an alternative approach to implementing the proposed DC-coupled PV-BES in PLEXOS and other PCMs. 


\section{PV-BES Hybrids}

A PV-BES system has two basic configurations: AC-coupled and DC-coupled (Figure 1). The AC-coupled system in Figure 1a consists of a PV system and a storage system connected to a common point on the AC grid. This configuration has advantages when retrofitting storage to an existing PV installation because (a) it avoids the need to replace the PV inverter and (b) it allows the BES to be deployed on the periphery of the previously developed PV system (Fu, Remo, and Margolis 2018). From an operational standpoint at the system level, an AC-coupled system is largely functionally equivalent to independent systems. Consequently, there is little need to develop new models in a PCM environment. ${ }^{1}$

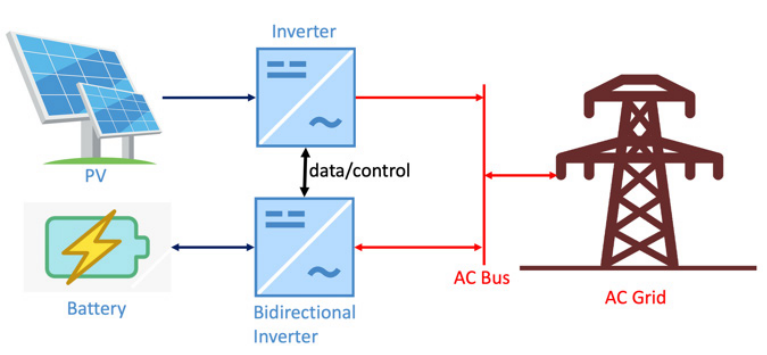

(a)

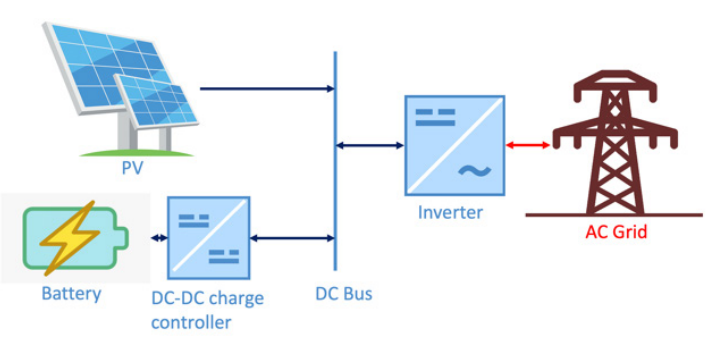

(b)

Figure 1. PV-BES hybrid configurations, including (a) an AC-coupled system with inverter communication link and (b) a DC-coupled system with grid charging capabilities using a bidirectional inverter

Figure $1 \mathrm{~b}$ illustrates a DC-coupled PV-BES hybrid, which is the focus of the present study. In a DC-coupled configuration, the PV and BES are connected on the DC side of a shared inverter which, in this case, is bidirectional (thus enabling the battery to charge from PV or from the grid). Because of the shared inverter, this configuration requires additional constraints and provides additional benefits that are typically not captured in a PCM without modification. The primary constraint is the shared inverter, which reduces operational flexibility of the PV and battery compared to independent components. Benefits include increased efficiency when charging from PV due to fewer conversion losses (DiOrio, Denholm, and Hobbs 2020). In addition, DC coupling of the PV and battery components enables the ability to recover PV generation that would otherwise be clipped by the inverter.

A special case of the DC-coupled system is one where a unidirectional inverter is used and the battery can charge only from the PV system to which it is coupled. This configuration removes several of the degrees of freedom of operation and is easier to implement. It also shares many similarities with concentrating solar power with thermal energy storage (CSP-TES), and therefore can be implemented by adapting existing model formulations for CSP-TES if available (Jorgenson et al. 2018).

\footnotetext{
${ }^{1}$ The battery inverter could have a communication link with the PV inverter to modify the charge control strategy based on the PV power availability. Such an operational coupling would require alteration of the PCM formulation.
} 
In addition to basic configurations, there are several other important aspects of modeling PVBES plants. The first is the relative sizing of the components, particularly the impact of the inverter loading ratio (ILR). The ILR, or DC-to-AC ratio, represents the sizing of the PV panels (rated in DC power) relative to the inverter output power (rated in AC). The ILR for a typical PV system is about 1.3, which increases utilization of the inverter and, in turn, reduces the overall system levelized cost (Good and Johnson 2016; Martins Deschamps and Rüther 2019). Higher ILRs will increase the amount of time the panels produce more energy than can be used, increasing clipped energy during the peak-solar hours of the year. A DC-coupled system can recover this otherwise clipped PV energy and enable even higher ILRs, thus potentially reducing levelized system costs. Detailed discussion of the components of a PV-BES systems is provided by (Bullich-Massagué et al. 2020; Wang, Ciobotaru, and Agelidis 2014; Hu et al. 2018; Miñambres-Marcos et al. 2017; Chen, Huang, and Yu 2013).

A second important issue is the objective of the modeling exercise and consideration of the perspective of the plant owner/operator. A properly designed PCM will optimize the system operation to minimize system costs. The PCM does not maximize revenue, nor does it necessarily consider certain policies that could result in dispatch that deviates from the systemwide least cost. An example is the impact of the federal investment tax credit: if more than $75 \%$ of the energy discharged from the battery is sourced from a coupled PV system, then a fraction of the battery's capital costs can qualify for the investment tax credit. In addition to the credit, other federal and state incentives might increase the amount of PV charging, including eligibility for the Modified Accelerated Cost Recovery System and availability of renewable energy credits (Elgqvist, Anderson, and Settle 2018). Consequently, PCM modeling of hybrid plants must consider the impact of dispatch decisions and the monetization of services provided by storage. In particular, a PCM formulation should represent all the components and flows of the PV-BES hybrid and track the percentage of the energy source charging the BES, in order to represent the impacts of the various policy incentives. The following section presents a technique to implement PV-BES in a commercial PCM software. 


\section{PV-Storage Hybrid Production Cost Modeling}

The objective of a PCM is to minimize the operational (or production) cost of all generators, such that the generation meets the load requirement at least cost while not violating any system constraints. The objective function of a PCM can be represented using Equation (1), where $P_{g}^{t}$ is the electricity produced by generator $g$ at time point $t$; $C_{g}$ is the incremental generation cost (including fuel and variable operation and maintenance costs); $S_{g}$ is the cost of starting generator $g$; and $y_{g}^{t}$ is a binary variable denoting the startup of the generator $g$. It is further subject to system constraints, which include (but are not limited to) generator operational constraints (Equation 2), demand $\left(P_{d}^{t}\right)$ and generation balance (Equation 3), and transmission line constraints (Equation 4), where $P_{l}^{t}$ is the power flow in line $l$ during interval $t$, and the $P_{l}^{\max }$ is the flow limit of line $l$.

$$
\min \sum_{t \in \tau} \sum_{g}\left(C_{g} P_{g}^{t}+S_{g} y_{g}^{t}\right)
$$

subject to:

$$
\begin{aligned}
& \mathrm{P}_{\mathrm{g}}^{\min } \leq \mathrm{P}_{\mathrm{g}}^{\mathrm{t}} \leq \mathrm{P}_{\mathrm{g}}^{\max } \\
& \sum_{g} P_{g}^{t}=P_{d}^{t} \\
& P_{l}^{t} \leq P_{l}^{\max }
\end{aligned}
$$

Our implementation of PV-BES hybrids builds on previous work modifying PCMs to represent CSP-TES systems (Jorgenson et al. 2018; 2013; Mehos et al. 2015). To include PV-BES using Equation 1, the simulation object must be able to (a) generate a time-series flow of energy from the PV to BES, PV to the grid, BES to the grid, and grid to the BES, and (b) optimize these flows to minimize costs. Therefore, the simulation object must constitute separate PV and BES objects within a generator object in order to calculate these flows. The simulation objects and their properties that are necessary for DC-coupled PV-BES are presented in Figure 2 (page 6), including a PV object, a storage object, an inverter (flow object), and a converter (flow object).

The PV object is characterized by its nameplate DC power $\left(P_{D C}^{\max }\right)$ relative to the $\mathrm{AC}$ rating of the inverter $\left(P_{\text {inv }}\right)$, as defined by the ILR in Equation (5).

$$
I L R=\frac{P_{D C}^{\max }}{P_{\text {inv }}}
$$

The bidirectional inverter (blue) is used for (a) PV-to-grid generation, (b) battery-to-grid discharge, and (c) grid-to-battery charging. The DC-DC converter (purple) is used for (a) PV-tobattery charging, (b) battery-to-grid discharge, and (c) grid-to-battery charging (via the inverter). The key characteristics of these devices are power rating and efficiency, resulting in three effective efficiencies for the different operating modes: PV-to-battery, PV-to-grid, and grid-tobattery. 


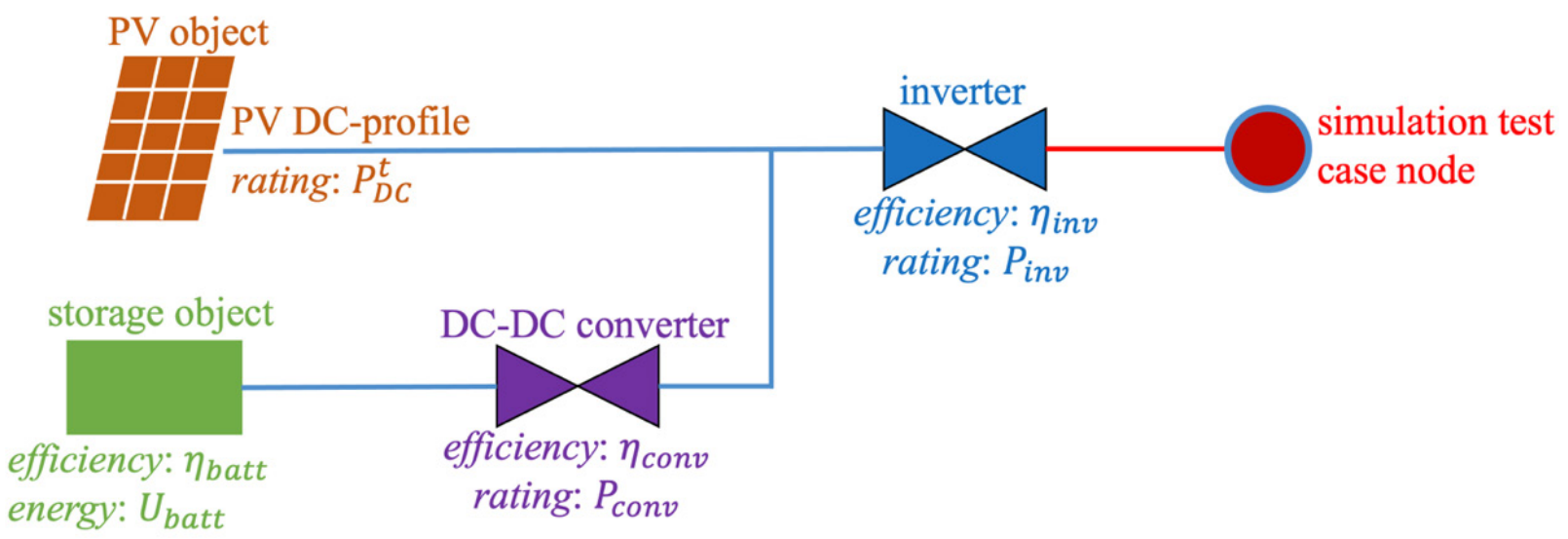

Figure 2. Simulation components that a PV-BES object must represent, along with their efficiencies and ratings for PCM analysis

Finally, the storage device is characterized by its efficiency, energy capacity, and power capacity, where the power capacity is ultimately limited by the rating of the DC-DC converter and inverter.

Commercial PCMs typically include PV and battery objects. However, linking those objects without modification would likely not result in an adequate PV-BES representation because of the unique aspects of DC-coupled systems. Therefore, additional modifications (or parameterizations) may be needed to capture the unique properties of PV-BES. For example:

- PV objects in commercial PCMs are typically represented by a time-series profile of AC power availability; this profile is generated by an external modeling tool that accounts for local solar conditions and component sizing, including ILR, inverter efficiency, ${ }^{2}$ and other wiring and interconnection losses based on the system design (panels and inverter arrangement). To adequately represent avoided clipping and improved efficiencies in PVBES, the model needs to use a time series DC profile $\left(P_{D C}^{t}\right)$ from the PV modules, which helps capture the potential to increase total output by recovering (and shifting) otherwiseclipped energy.

- Storage objects in commercial PCMs are typically defined by their energy rating $\left(U_{\text {batt }}\right)$, the power rating of the inverter, and the roundtrip efficiency of the complete system (including battery, power electronics, and parasitic-related losses). In representing PVBES, the battery object would ideally allow for separate efficiencies for each charging source (grid, local PV), such that the efficiency of the storage $\left(\eta_{\text {batt }}\right)$ is represented separately based on the round-trip battery pack efficiency (including the battery internal and interconnection losses and certain parasitics not associated with charging). The battery power must also be limited by the power rating of the DC-DC converter $\left(P_{\text {conv }}\right)$.

\footnotetext{
${ }^{2}$ For example, the inverter model within NREL's System Advisor Model (Freeman et al. 2018) generates such profiles, based on libraries of performance data for PV inverters. The underlying performance parameters are derived from empirical data regarding the relationship between DC input and AC output for grid-connected PV inverters, as well as the self-consumption of the inverter itself under a range of operating and environmental conditions (King et al. 2007).
} 
- Most commercial PCMs do not have separate inverter and DC-DC converter objects, so they cannot represent the dynamic behavior of these components. In their native forms, the power rating of the entire PV-BES system would be defined by the hybrid-inverter $\left(P_{\text {inv }}\right)$; an ideal representation of PV-BES would allow the inverter and DC-DC converter efficiencies to be considered separately.

There are potential tradeoffs in (a) modeling details associated with the modifications outlined above and (b) capturing changes in the different operating modes associated with a DC-coupled PV-BES. Overall, a DC-coupled PV-BES with bidirectional inverter can operate in seven different modes:

- PV-to-grid

- PV-to-grid and PV-to-battery

- PV-to-battery only

- Grid-to-battery

- Battery-to-grid

- Battery-to-grid and PV-to-grid

- PV-to-battery and grid-to-battery.

The efficiency of charging the battery from the PV system $\left(\eta_{b a t t}^{P V}\right)$ as in Equation (6) is greater than the efficiency of charging from the grid $\left(\eta_{\text {batt }}^{\text {Grid }}\right)$, which includes the inverter efficiency as shown in Equation (7).

$$
\begin{aligned}
& \eta_{\text {batt }}^{\text {PV }}=\eta_{\text {conv }} \eta_{\text {batt }} \\
& \eta_{\text {batt }}^{\text {Grid }}=\eta_{\text {inv }} \eta_{\text {conv }} \eta_{\text {batt }}
\end{aligned}
$$

As a result, a detailed model of a DC-coupled system requires representing both the inverter and DC-DC converter, which increases complexity relative to the AC-coupled or independent systems. This increased complexity may not be justified if the magnitude of reduced losses associated with PV charging are small (DiOrio, Denholm, and Hobbs 2020).

Further complicating the issue is that the introduction of the DC inverter object in a PCM environment likely results in a loss in modeling fidelity of the PV performance. For example, detailed inverter models in simulation tools that typically generate AC profiles (e.g., the National Renewable Energy Laboratory's System Advisor Model, or SAM) are designed to capture the complicated nonlinear characteristics of inverters. ${ }^{3}$ In this study, the DC module production is modified by a single inverter efficiency to generate AC profiles, which are separated in order to

\footnotetext{
${ }^{3}$ Empirical evidence indicates that the relationship between measured AC and DC power associated with gridconnected PV inverters is nearly linear, regardless of operating and environmental conditions (e.g., rapid changes in cloud cover). However, the inverter efficiency itself (AC power divided by DC power) is nonlinear because of varying levels of self-consumption at different voltage and power levels (King et al. 2007). The scatter in the efficiency measurements resulted from a combination of variation in DC input voltage, inherent inverter behavior, rapidly varying solar irradiance, and measurement error.
} 
quantify the utilization of energy that would otherwise be clipped (within a detailed inverter model outside PLEXOS).

To estimate the impacts of a simplified inverter representation, we compare AC output from a specific PV system using (a) the detailed inverter model included in $\mathrm{SAM}^{4}$ and (b) outputs based on the approach proposed in this report. Using the same DC production information for a PV array with a DC rating of $570 \mathrm{MW}$ and $\mathrm{ILR}=1.3$ in Barren Ridge, California, we find that the annual AC output is 327 gigawatt-hours (GWh) based on a simulation in SAM, compared to 335 $\mathrm{GWh}$ based on the current approach. In other words, the use of a single inverter efficiency value results in a $2.7 \%$ increase in AC output for ILR=1.3, compared to that simulated with a more detailed inverter model. This difference further depends on the assumed ILR, and it declines to $1.8 \%$ for ILR $=1.8$. Given the magnitude of impact, this limitation should be noted, but it does not diminish the outcomes or findings of this analysis, which are focused on modeling a system that can study the flow and interaction between the AC and DC sides of a hybrid setup.

We implement the model presented above in PLEXOS, a commercial PCM. Commercial PCMs are typically not open source, and changes must typically be used to modify existing capabilities. Our example uses the PLEXOS commercial PCM and objects and constraints that already exist in the tool. There can be multiple techniques to implement a PV-BES in a PCM software, and in this paper, we present an approach using the storage-generator topology, which is similar to the approach used for implementing CSP-TES (Jorgenson et al. 2018).

In this approach, we use generator objects to represent inverters and hydro-storage objects to represent the battery and energy inflow (the PV generation). Figure 3 presents the schematic of the storage-generator topology, using standard PLEXOS objects. ${ }^{5}$ The PV component of the PVBES is defined by three linked objects:

1. A head storage object represents the DC generation profile; it is set to not store any energy, and its natural inflow property is linked to the DC rating $\left(P_{D C}^{t}\right)$ of the $\mathrm{PV}$. The available "flows" for the PV energy, then, include sending it to the grid (through the connected generator, \#2 below) or to the battery (\#3 below).

2. A generator object represents the PV-inverter (blue triangles), where the rating property $\left(P_{P V}\right)$ is set equal to the inverter rating $\left(P_{i n v}\right)$, and the generator efficiency property is set equal to the inverter efficiency $\left(\eta_{\text {inv }}\right)$.

\footnotetext{
${ }^{4}$ The simulation uses 2012 weather year data for all PV profiles. The simulation is set up using a detailed PV plant model in SAM that includes $743 \mathrm{MW}$ of peak PV DC capacity and inverters that are sized to achieve ILR=1.3 (or 570 MW of PV AC capacity).

${ }^{5}$ Using PLEXOS terminology, the PV array is represented as a hydroelectric dam with no storage capacity; the inverter is represented as a hydroelectric generator; the battery is represented as a pumped-hydro system with tail and head storage reservoirs (where water in the "head" represents energy stored in the battery and water in the "tail" is equal to the difference between the maximum battery capacity and energy in the "head"); and the DC-DC converter is represented as a waterway linking the PV hydroelectric dam with the battery "head" reservoir.
} 
3. A waterway object represents the flow of PV generation to the DC-coupled battery; its flow limit property represents the DC-DC converter (or charge controller) rating $\left(P_{\text {conv }}\right)$, and its output scalar property represents the efficiency of the charge controller $\left(\eta_{\text {conv }}\right)$.

PV energy is spilled during intervals when additional PV energy cannot be utilized by either of these two flows (\#2 and \#3 above).

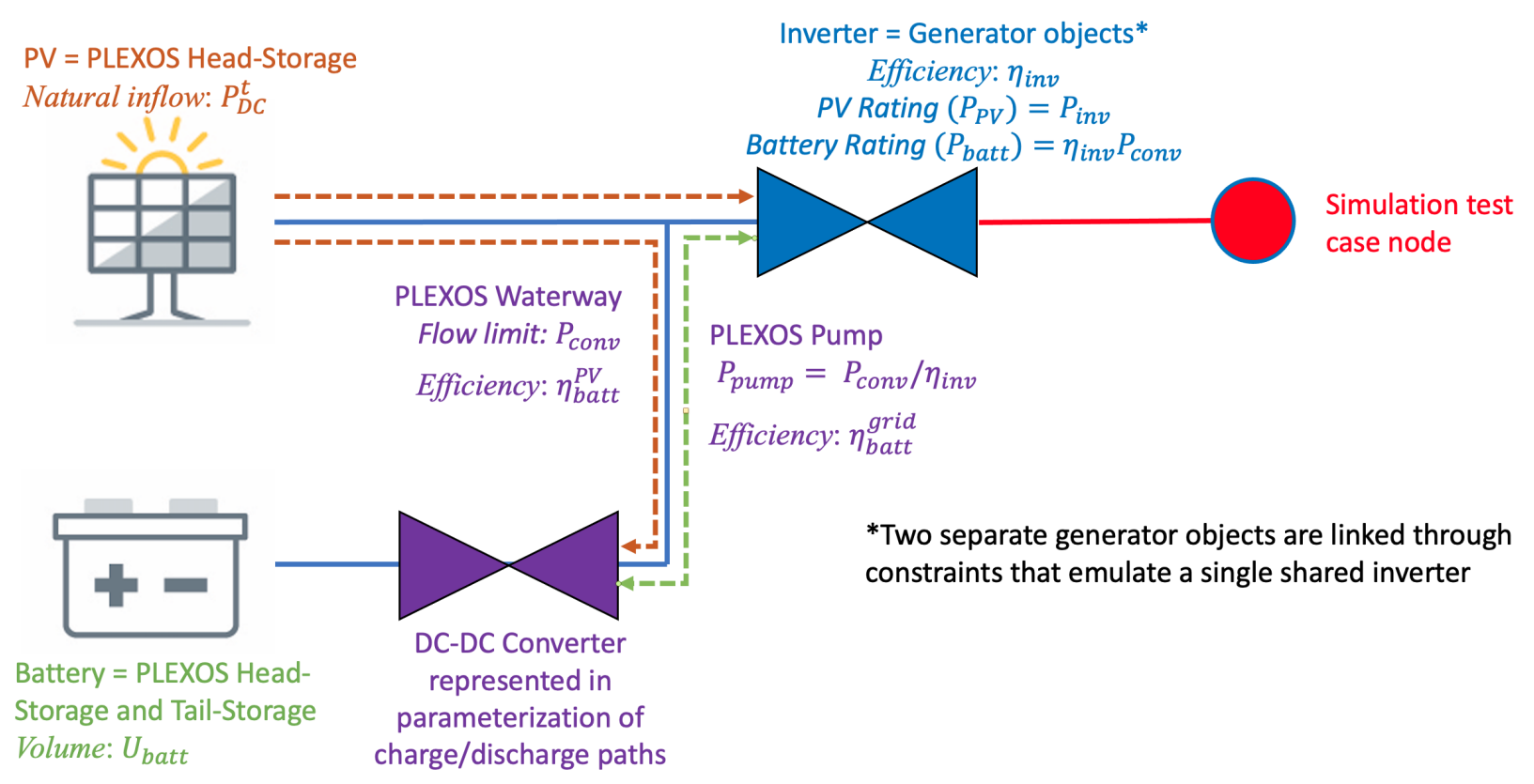

Figure 3. PLEXOS implementation of DC-coupled PV-BES using the storage generator topology

Inverters are represented using generator objects, and energy sources are represented using hydro-storage objects. Italicized text represents properties in PLEXOS.

* Equation (8) links the separate inverter objects to emulate a single inverter.

The battery component of the PV-BES is represented using a pumped-hydro generator object, which can "charge" through two pathways (represented by the arrows in Figure 3). The pump load property $\left(P_{\text {pump }}\right)$ represents the load on the system to charge the battery from the grid (red arrow). Charging from PV through the DC-DC controller is represented by the PLEXOS waterway object (\#3 above). The rating of the pumped-hydro generator object $\left(P_{\text {batt }}\right)$ is set to equal to the DC-DC converter rating times the inverter efficiency $\left(\eta_{i n v} P_{c o n v}\right)$, which defines the peak discharge capability of the battery at the AC node. This model provides the flexibility to have a different charge efficiency to charge the battery using each path (i.e., PV-to-battery or grid-to-battery via the shared inverter). Properties associated with pumped storage plants, such as minimum generation levels and ramp rate constraints, are set to zero.

The hybrid-inverter (blue in Figure 3) is responsible for PV-to-grid, battery-to-grid, and grid-tobattery flows. For the model in Figure 3 to represent a single inverter for all the flows, the ratings of each of the separate objects are constrained using Equation (8) so that any combination of PV generation $\left(P_{P V}^{t}\right)$, battery discharge $\left(P_{\text {batt }}^{t}\right)$, and grid charging $\left(P_{\text {pump }}^{t}\right)$ is less than or equal to the inverter rating $\left(P_{i n v}\right)$ for all intervals $(t)$ of the simulation $T$. 


$$
P_{P V}^{t}+P_{\text {batt }}^{t}+P_{\text {pump }}^{t} \leq P_{\text {inv }}, \forall t \in T
$$

The battery object efficiency is set to $100 \%$, and the losses corresponding to either energy source ( $\mathrm{PV}$ or grid) are incorporated into the charging efficiency of either path (PV or grid). Equation (6) is replaced with Equation (9) in order to represent the efficiency gains associated with charging from the PV and discharging to the grid (compared to charging from and discharging to the grid).

$$
\eta_{b a t t}^{P V}=\eta_{c o n v}^{2} \eta_{b a t t} \eta_{i n v}
$$

The squared converter efficiency $\left(\eta_{\text {conv }}^{2}\right)$ comes from the converter's charge and discharge actions, thus representing a roundtrip efficiency. Equation (7) is replaced with Equation (10) to represent the round-trip efficiency of the energy from and to the grid; this efficiency is set as the pump efficiency property for the PLEXOS battery generator object.

$$
\eta_{\text {batt }}^{\text {Grid }}=\eta_{\text {conv }}^{2} \eta_{\text {batt }} \eta_{\text {inv }}^{2}
$$

All the flows through the converter must be less than or equal to the converter capacity $\left(P_{\text {conv }}\right)$ as described in Equation (11):

$$
\eta_{\text {inv }} P_{\text {pump }}^{t}+P_{w w-\text { flow }}^{t}+P_{\text {batt }}^{t} / \eta_{\text {inv }} \leq P_{\text {conv }}
$$

where $\left(P_{w w-f l o w}^{t}\right)$ represents the flow through the waterway (PV-charging) at an interval $t$. The entire pump load (grid charging) does not fall on the converter, as some power is lost in the inverter; to represent these losses, the inverter efficiency $\left(\eta_{i n v}\right)$ is multiplied by the pump load $\left(P_{\text {pump }}^{t}\right)$. The inverter losses during the discharge cycle are included in the charging efficiency as described in Equation (9) and Equation (10). The energy discharge through the converter must be corrected for the inverter losses and, thus, is divided by the inverter efficiency as described in Equation (11).

The state of charge $(\mathrm{SoC})$ of the battery is derived by dividing the volume in head storage by the sum of the volume in head storage. The ability to discharge is determined by the volume available in the tail storage. Because of the two charging sources, the head storage can be filled without using the pump. A constraint is added such that at every time interval $t$, the volume of the head storage $\left(U_{\text {head }}^{t}\right)$ and tail storage $\left(U_{\text {tail }}^{t}\right)$ is equal to the battery capacity $\left(U_{\text {batt }}\right)$ for all intervals of the simulation $T$, as shown in Equation (12).

$$
U_{\text {head }}^{t}+U_{\text {tail }}^{t}=U_{\text {batt }}, \quad \forall t \in T
$$

In addition, the tail storage maximum spill property is set equal to $U_{b a t t}$ so that the energy balance of Equation (12) can be maintained when the head storage is being charged from PV, and the equivalent volume is spilled out of the tail storage so that the hydro model can generate electricity.

An alternative approach that uses the transmission line as an inverter is presented in the appendix. Though the transmission-line inverter topology approach produces similar results, we find that it increases the simulation time. 


\section{Capability Demonstration}

This section presents the validation of the proposed model through simulation of a real power system in PLEXOS. The simulation setup and the detailed validation results are presented in the following subsections.

\subsection{Simulation Setup}

To demonstrate our implementation of a PV-BES hybrid, we begin by defining its performance characteristics. In particular, we set efficiencies for the inverter $\left(\eta_{\text {inv }}\right)$, converter $\left(\eta_{\text {conv }}\right)$, and battery $\left(\eta_{\text {batt }}\right)$ to $97.3 \%, 99 \%$, and $92 \%$, respectively, following assumptions from the literature (Schimpe et al. 2018; Gilman et al. 2008; Mongird et al. 2020). See Table 1 for a summary and details associated with the available energy pathways. The value for parameter $\eta_{\text {batt }}$ assumes the battery pack efficiency that includes lithium-ion cell internal efficiency, battery interconnection efficiency, and the battery pack thermal losses based on (Schimpe et al. 2018).

Table 1. Equations and Values that Define the Efficiencies for Each Available Pathway

\begin{tabular}{lcc}
\hline \multicolumn{1}{c}{ Pathway } & Equation & Net Efficiency (\%) \\
\hline PV-grid & $\eta_{\text {inv }}$ & 97.3 \\
Grid-battery-grid & $\left(\eta_{i n v}{ }^{2}\right)\left(\eta_{c o n v}{ }^{2}\right) \eta_{b a t t}$ & 85.4 \\
PV-battery-grid & $\left(\eta_{\text {conv }}{ }^{2}\right) \eta_{\text {batt }} \eta_{i n v}$ & 87.7 \\
\hline
\end{tabular}

\section{Test System}

Next, we add our PV-BES technology to a test system based on the LADWP generation and transmission system. In particular, we use a test system that leverages data sets developed for the Los Angeles 100\% Renewable Energy (LA100) Study (Cochran and Denholm 2021) based on the 2020 capacity mix (first column Table 2, page 12).

The model has 108 nodes and 189 branches with an annual demand of 28.4 terawatt-hours (TWh), peaking at 6,723 MW. Some of these generation technologies are an aggregation of subtechnologies; for example, PV includes rooftop PV, distributed PV, and utility-scale PV. Timeseries data include hourly load (generated as part of the LA100 study), hourly PV generation profiles from the National Solar Resource Database (using 2012 meteorological conditions), and hourly wind profiles from AWS Truepower (using 2012 meteorological conditions). "Demand Response" is flexible demand that can be curtailed or shifted. Performance of the thermal fleet (e.g., heat rates) are based on data from the LA100 study. The PV-Battery generators in the base representation of the LADWP system are AC-coupled PV-BES systems with ILR=1.3.

\section{PV-BES Plants}

To implement our new PV-BES hybrid technology, we modified assumptions for five of the $P V$ Battery generators on the LADWP test system (Table 2). The combined capacity of these five PV plants is 1,326 MW (of 1,401 MW for the PV-Battery category), which represents $13 \%$ of the total installed capacity $(10,694 \mathrm{MW})$. The power rating of the inverter and converter, and the energy rating of the battery for the five existing plants are adopted for this study. Power and 
energy ratings and the nameplate PV DC rating for these five plants are presented in Table 3 (page 13).

All the PV-BES constraints discussed in Section 3 are applied. The peak power from battery is set to half the peak DC power of the PV (for ILR=1.3), and its energy rating is based on an assumption of 4 hours of usable peak power; in other words, the battery component will experience $100 \%$ depth of discharge after operating for 4 hours at the peak power rating; or, more likely, the storage rating can be interpreted as a battery whose nameplate energy capacity has already been adjusted to account for SoC restrictions. Though this distinction would have important implications for investment costs, it does not impact the operational characteristics presented here. This sizing (or any of the other aspects of the systems analyzed) is not intended to be optimal but is used just to evaluate the performance of the overall modeling approach.

\section{Scenario Design}

Using the LADWP test system, our PV-BES implementation, and our assumed PV-BES sizing, we define scenarios that isolate drivers of operational strategies for hybrid system, including the effects of DC coupling, PV penetration, and ILR for the PV-BES hybrids.

The effects of $D C$ coupling are explored with scenarios that compare operational behavior of AC-coupled and DC-coupled configurations (see Figure 1) for PV-BES with ILR=1.3. Comparing the operational behavior of scenarios with the same sizing but different architectures enables verification of the utilization of clipped energy and evaluation of the impacts of varying efficiencies for each available energy pathway.

Table 2. Capacity Inputs and Generation Outputs for all Generators in the LADWP System

\begin{tabular}{lrrr}
\hline & Capacity (MW) & \multicolumn{2}{c}{ Energy (GWh) } \\
\hline Generator Type & All Scenarios & Base Case & 1/2 PV Sensitivity \\
\hline Biomass & 22 & 1.4 & 1.8 \\
Coal & 1,679 & 8,578 & 8,930 \\
Demand Response & 44 & 0.8 & 1.5 \\
Gas-CC & 2,362 & 4,212 & 5,545 \\
Gas-CT & 881 & 789 & 1,040 \\
Gas-Steam & 712 & 82 & 116 \\
Geothermal & 235 & 1,834 & 1,838 \\
Hydro & 726 & 1,661 & 1,633 \\
Nuclear & 394 & 3,271 & 3,272 \\
Pumped-Hydro & 427 & 17 & 18 \\
PV & 621 & 1,063 & 1063 \\
PV-Battery & 1,401 & 5067 & 2,995 \\
Storage & 147 & 6,683 & 3.3 \\
Wind & 1,000 & $\mathbf{2 9 , 2 7 7}$ & 2,685 \\
\hline Total & $\mathbf{1 0 , 6 9 4}$ & $\mathbf{2 9 , 1 4 2 ^ { \mathbf { a } }}$ \\
\hline
\end{tabular}

a The 1/2 PV Scenario has a lower total generation than the full-PV case for the same demand because of reduced use of storage that decreases demand on the system. The reduced PV results in increase of coal and natural gas generation that results in higher prices that discourages use of storage. 
The effects of $P V$ penetration on PV-BES operation and value are explored via the $1 / 2 \mathrm{PV}$ Scenario, in which total PV generation (including PV-BES) on the LADWP test system is halved and all PV-BES hybrids are implemented as DC-coupled systems with ILR=1.3.

The effects of increasing ILR from 1.3 to 2.0 are explored by fixing the AC rating of the inverter and increasing the PV DC rating, with the resulting nameplate DC ratings shown in Table 3. Comparing the operational behavior of scenarios with different ILRs enables evaluation of how excess PV production is utilized in DC-coupled systems.

Table 3. Details of the DC-Coupled PV-BES Implemented in the Base Case LADWP System

\begin{tabular}{lrrrrr}
\hline Parameter & Plant 1 & Plant 2 & Plant 3 & Plant 4 & Plant 5 \\
\hline Location & $\begin{array}{r}\text { Eldorado } \\
\text { Valley, NV }\end{array}$ & Azusa, CA & $\begin{array}{r}\text { Barren } \\
\text { Ridge, CA }\end{array}$ & $\begin{array}{r}\text { Barren } \\
\text { Ridge, CA }\end{array}$ & Lockhart, CA \\
\hline$P_{\text {inv }}(\mathrm{MW})$ & 210 & 250 & 570 & 90 & 205 \\
$P_{\text {conv }}(\mathrm{MW})$ & 137 & 163 & 371 & 59 & 134 \\
$U_{b a t t}(\mathrm{MWh})$ & 546 & 650 & 1,482 & 234 & 535 \\
$P_{D C}^{\max }$ ILR 1.3 (MW) & 273 & 325 & 741 & 117 & 266 \\
$P_{D C}^{\max }$ ILR 1.4 (MW) & 294 & 350 & 798 & 126 & 287 \\
$P_{D C}^{\max }$ ILR 1.5 (MW) & 315 & 375 & 855 & 135 & 307 \\
$P_{D C}^{\max }$ ILR 1.6 (MW) & 336 & 400 & 912 & 144 & 328 \\
$P_{D C}^{\max }$ ILR 1.7 (MW) & 357 & 425 & 969 & 153 & 348 \\
$P_{D C}^{\max }$ ILR 1.8 (MW) & 378 & 450 & 1,026 & 162 & 369 \\
$P_{D C}^{\max }$ ILR 1.9 (MW) & 399 & 475 & 1,083 & 171 & 390 \\
$P_{D C}^{\max }$ ILR 2.0 (MW) & 420 & 500 & 1,140 & 180 & 410 \\
\hline
\end{tabular}

All simulations are carried out using PLEXOS Version 8.2 using the Xpress-MP solver. The 2020 scenario is chosen as the simulation horizon with one-hour resolution and one-day lookahead. All the DC profiles $\left(P_{D C}^{t}\right)$ for the PV-BES are developed using the National Renewable Energy Laboratory's System Advisor Model (SAM) (Freeman et al. 2018) based on 2012 weather data.

All renewable energy resources are assumed to supply energy at zero cost. We use variable costs of $0.1 \$ / \mathrm{MWh}$ for the battery to avoid degeneracies (related to PV versus battery dispatch) and unrealistic battery cycling. The relatively low value assumed allows for the optimization to dispatch the battery as a resource without resulting in curtailment because of cost. These cost components are not meant to reflect realistic variable costs for battery technologies; rather, they are used to study the operation of the proposed PV-BES hybrid in a PCM. All other generators have technology-specific operational constraints as well, based on the native PLEXOS representation.

Operation of the DC-coupled PV-BES is demonstrated in the following subsections. In Section 4.2, we demonstrate the various modes of operation that are available for a PV-BES hybrid and discuss the impacts of PV penetration on PV-BES operations and value. In Section 4.3, we 
compare the operations for different PV-BES configurations, including AC-coupled vs. DCcoupled architectures and the impact of increasing ILRs; the latter presentation includes how operational strategies evolve with a growing amount of otherwise-clipped energy and corresponding impacts on production costs.

\subsection{Results: PV-BES Modes of Operation}

Seven different operating modes are possible for a DC-coupled PV-BES plant. Figure 4 (page 15 ) illustrates six of these modes during two days of operation (July $12^{\text {th }}$ and $13^{\text {th }}$ ) for Plant 3 in the case with ILR $=2.0{ }^{6}$ For each hour interval, the left-side orange bars represent the available PV-DC power; the right-side stacked bars represent any one of the seven operating modes for the $\mathrm{PV}$ and/or battery component, including:

1. PV only to grid (dark red bar): This mode is typically observed in hours when the available PV DC power (orange bars) is lower than the inverter rating (e.g., 5 a.m. on July $12^{\text {th }}$ and $\left.13^{\text {th }}\right)$.

2. Battery only to grid (teal bar): This mode can be observed in evening hours when PV DC power is zero and demand is fairly high (e.g., hours 20-22 [8 p.m.-10 p.m.] on July $12^{\text {th }}$ ).

3. PV and battery to grid (dark red and teal bars): This mode is observed when the available solar energy is lower than the inverter rating and load is relatively high (e.g., hour 16 [4 p.m.] on July $12^{\text {th }}$, and hour 18 [6 p.m.] on July $13^{\text {th }}$ ).

4. PV only to battery (yellow bar): This mode would be expected during times of lower demand (e.g., spring), and it is not observed on July $12^{\text {th }}$ or July $13^{\text {th }}$.

5. PV to grid and battery (dark red and yellow bars): This mode is common in peak solar hours when the available PV DC power is above the inverter rating (e.g., hours 10-14 [10 a.m. -2 p.m.] on July $12^{\text {th }}$ and hours 6-17 [6 a.m. -5 p.m.] on July $13^{\text {th }}$ ).

6. Grid to battery (purple bar): This mode is typically observed when no PV is available and the system foresees a low PV day (e.g., hours 1-4 [1 a.m. -4 a.m.] on July $12^{\text {th }}$ ).

7. PV and grid to battery (yellow and purple bars): This mode is observed when the system foresees lower PV DC power during high load times and charges the battery (e.g., hours 6-8 [6 a.m. -8 a.m.] on July $12^{\text {th }}$ ) in preparation for meeting load at a later period.

Figure 4 also indicates several constraints of the system. For example, the system can avoid clipping when the DC output is greater than the inverter rating (570 MW in Figure 4) by storing energy (see hours 7-15 on July 15). However, the amount of avoided clipping is restricted by the size of the battery. PV energy is spilled in hours $11,14,15$, and 16 on July 15 , because the total available PV DC power on this day is greater than the total power capacity of the battery and inverter.

Note that the specific daytime hours during which PV energy is spilled is somewhat arbitrary, due to both the perfect foresight (or "forecastability") associated with the optimization and degeneracies in the solution. In particular, the model "knows" that (a) it can achieve a near-100\% SoC via the use of otherwise clipped energy and (b) a non-zero amount of spilled energy is required (based on the PV-BES energy balance constraints). So, its charging behavior can appear

\footnotetext{
${ }^{6}$ See Table 3 for details about the sizing of this specific setup for Plant 3.
} 
somewhat erratic as a result of modest changes in the nodal price during the day, whereas similar overall results would be produced if the spilling occurred during different daytime hours.

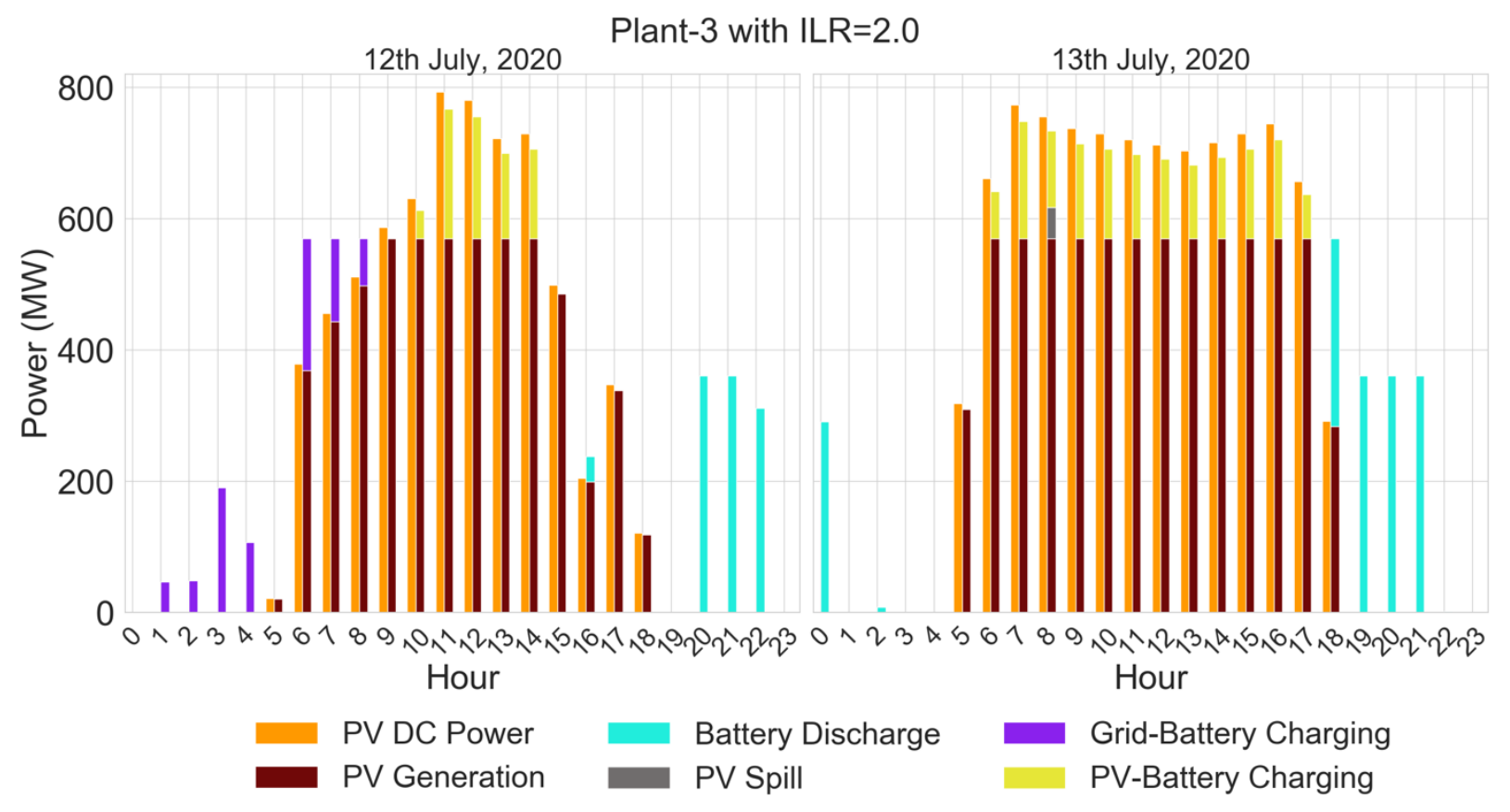

Figure 4. Hourly operation of DC-coupled PV-BES Plant 3 with ILR=2.0 on July 12 and 13

The left-side Orange bars represent the available PV-DC power, and the right-side stacked-bars represent an operating mode of either PV or battery.

Finally, Figure 5 presents the grid charging patterns for a single day (July 11, 2020) from the 1/2 PV Scenario. This scenario is designed to explore different levels of grid charging, which is sensitive to the level of PV penetration; in other words, increasing PV penetration on the system more broadly tends to depress energy prices during the daytime hours, thus incentivizing the PVBES hybrids to charge from local PV during those hours.

Comparison of panels in Figure 5 reveals that the dominant impact of PV penetration is to shift the timing (and source) of charging for the battery component and, to a lesser extent, its discharging. In particular, if we assume a significantly lower penetration of PV (left panel), then battery charging occurs in the non-solar hours. This shift reflects the interactions with energy prices, as charging the battery overnight (hours 0-6) corresponds to a period when demand on the system is low, such that additional charging demand does not increase the production cost significantly (based on Equations (1) and (2)). Some of this stored energy is then used during a midday drop in solar irradiation (hours 14-16), which results in a lower production cost. However, in both cases, most of the battery discharging occurs during the evening hours, when demand ramps up and solar energy reduces. 


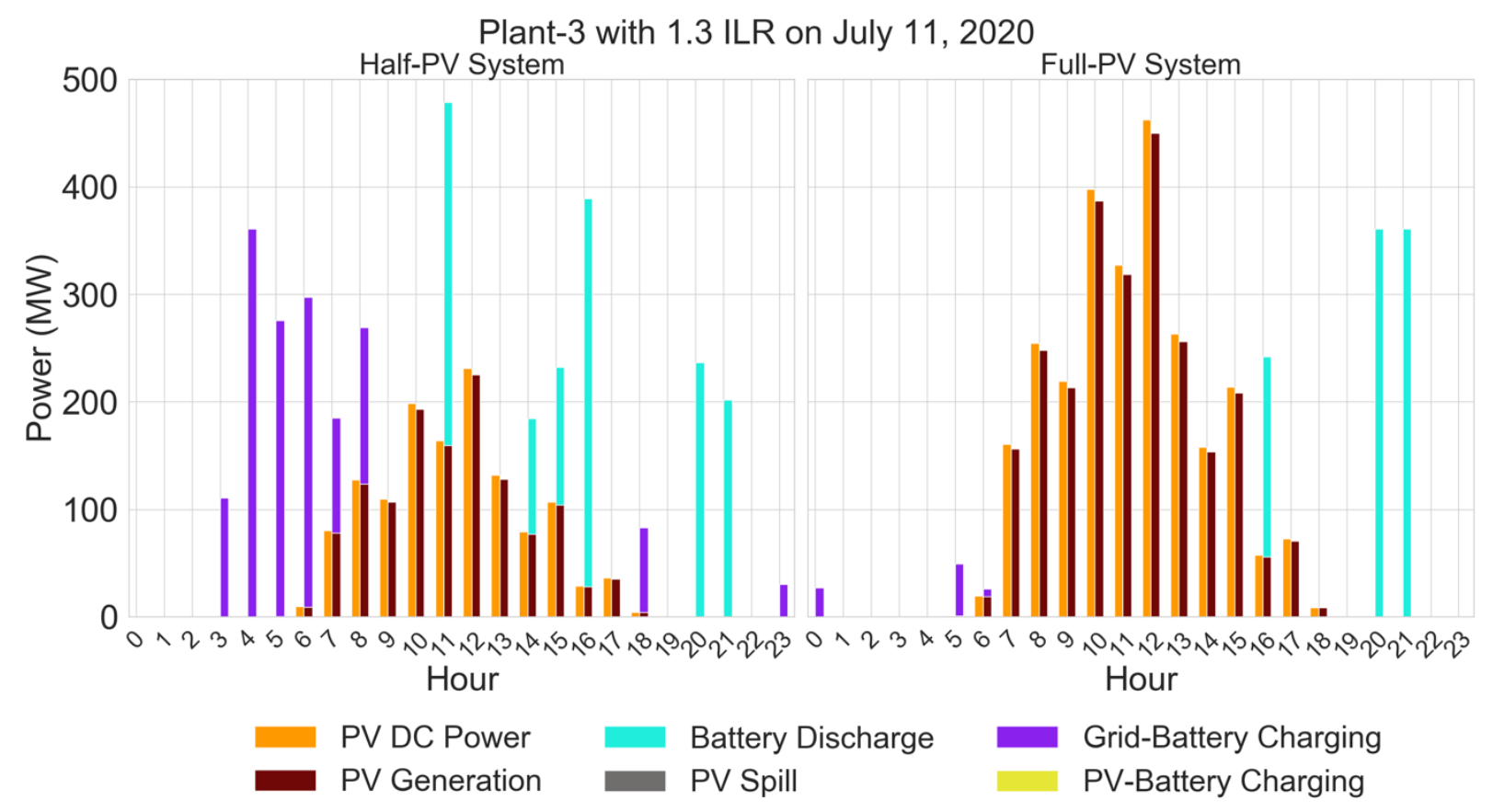

Figure 5. Hourly operation of DC-coupled PV-BES Plant 3 in ILR 1.3 on July 11, 2020 in the 1/2 PV Scenario (left) and ILR=1.3 scenarios

\subsection{Results: Impact of Configuration}

As previously stated, PV-BES configuration is defined by both the nature of coupling between and relative sizing of the PV and battery components. Direct comparison between coupling types is most meaningful when the PV DC rating is fixed at a level that is appropriate for an ACcoupled system. However, for an ILR of 1.3, there is limited opportunity for the DC-coupled system to realize its primary benefit (recovering otherwise-clipped generation) over the ACcoupled system. ${ }^{7}$ Table 4 presents a comparison of results for AC-coupled and DC-coupled PVBES with an ILR of 1.3 , which reveals a difference in production cost of just $0.1 \%$ (due to utilizing the modest amount of clipped energy and a slightly more efficient charging efficiency).

Table 4. Summary of annual parameters for AC coupled, and DC coupled system at ILR 1.3

\begin{tabular}{ccc}
\hline Parameter & AC-Coupled & DC-Coupled \\
\hline Production cost & $\$ 368,140,000$ & $\$ 367,810,000$ \\
PV generation & $19,600 \mathrm{GWh}$ & $19,000 \mathrm{GWh}$ \\
Battery discharge & $4,950 \mathrm{GWh}$ & $4,990 \mathrm{GWh}$ \\
PV DC charging & 0 & $730 \mathrm{GWh}$
\end{tabular}

The remainder of this section explores how higher ILRs will change the operation of the battery and the resulting benefits to the system. In particular, the ILR associated with a DC-coupled PV-

\footnotetext{
${ }^{7}$ Based on 2012 weather year data and an ILR of 1.3 , only $0.4 \%$ of the total annual available DC energy produced by the PV array is clipped (i.e., it exceeds the inverter rating).
} 
BES influences the amount of energy produced by the DC modules, which influences both operational strategies and production cost over the course of the simulation period (one year). To demonstrate this effect, Figure 6 presents the aggregated discharge energy of the battery component (bars) throughout the year, which is overlaid with the SoC distributions for the intervals during which the battery component discharges. For the sake of clarity, Figure 6 only presents the details for the ILR=1.3 and ILR=2.0 DC-coupled PV-BES, because the values of the other configurations follow a similar pattern and can be understood by interpolating between the presented results.

Looking across the time intervals presented in Figure 6, it is apparent that most of the battery discharge for the PV-BES units happens during the evening hours, when the solar irradiance decreases and energy demand increases. In the absence of storage units, gas generators are often used during this period. However, in our scenarios, energy from the battery component of the PV-BES hybrid is utilized instead, which reduces the need for expensive generators and, in turn, reduces the system-wide production cost.

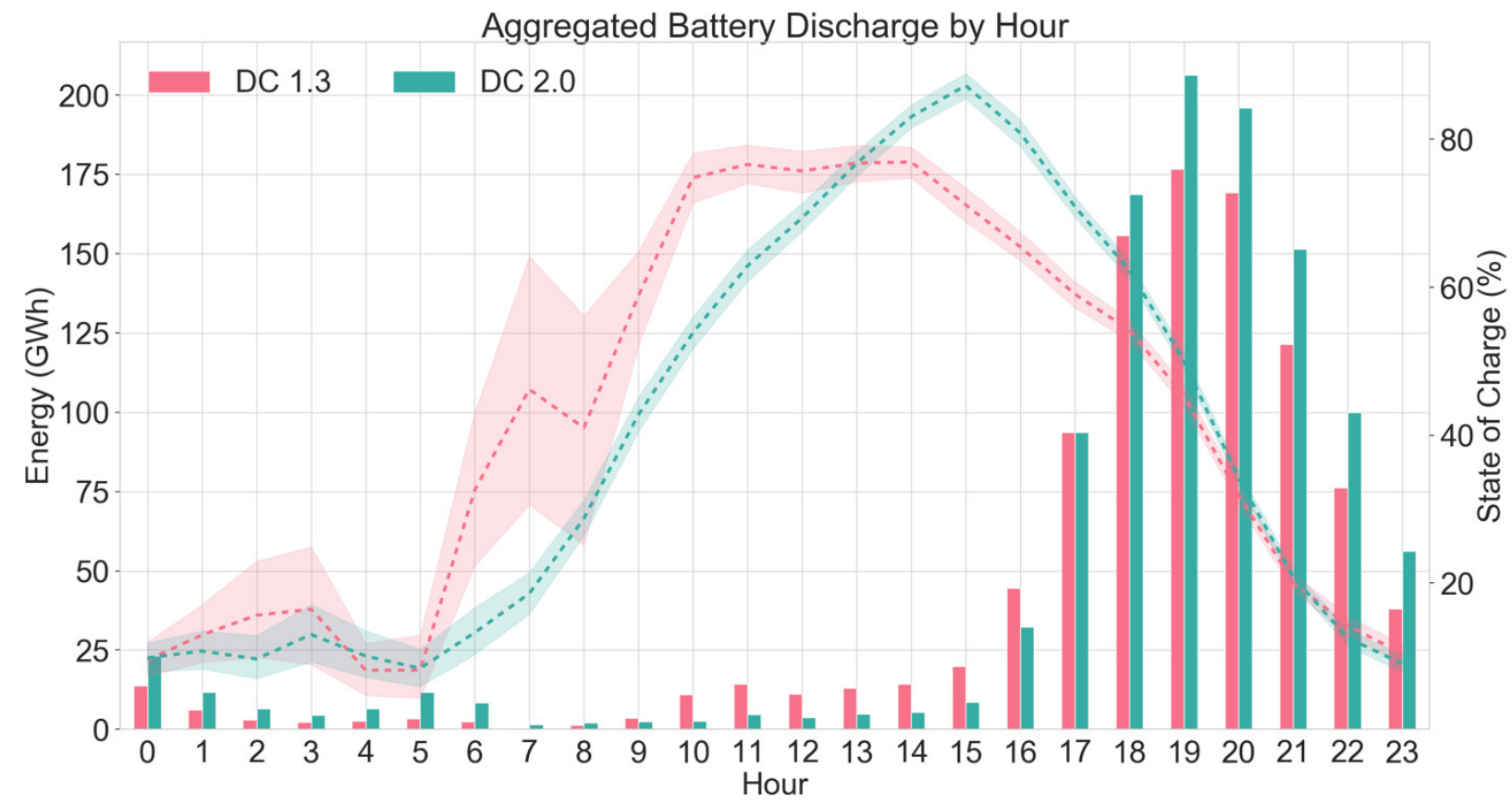

Figure 6. Battery discharge behavior for the battery component of the DC-coupled PV-BES hybrids with ILR 1.3 (pink) and 2.0 (green), aggregated over the 1-year analysis period

The bar plot represents the aggregated hourly battery generation; the dotted lines represent the mean of the SoC for the intervals during which the battery component discharges, and the shaded area is the $95 \%$ confidence range of this price distribution.

Also depicted in Figure 6 are the different SoC paths and operational strategies for the battery component in PV-BES hybrids with ILR=1.3 (pink) and ILR=2.0 (green). The green dashed line and narrow distribution around it indicates that the SoC for a high-ILR system follows a similar path throughout the year, such that the battery component charges from the otherwise-clipped energy throughout (and almost exclusively) during the daytime hours. Consequently, the battery component's SoC increases steadily throughout the day and enters the evening period with an SoC that is near-100\% and consistently higher than PV-BES hybrids with ILR $=1.3$. The SoC 
path for the PV-BES hybrid units with ILR=1.3 also differs more throughout the year (as demonstrated by the wider range around the pink dashed line), although the trends are consistent and similar to those observed for the higher ILR hybrid units.

Looking across all hours of the year and configurations, the utilization of the PV-BES hybrid's inverter can be evaluated through a variety of aggregate metrics:

- Capacity factor is defined as the total amount of energy produced by the plant divided by annual energy at full output rating of the $\mathrm{AC}$ inverter. This is essentially the same as the capacity factor of a conventional power plant.

- The grid charging factor is the ratio of the energy drawn from the grid (AC-to-DC) for charging the battery to the annual energy at full output rating of the $\mathrm{AC}$ inverter.

- The utilization factor is the ratio of the total energy passed through the inverter (AC-to$\mathrm{DC}$ and DC-to-AC) to the annual energy at full output rating of the AC inverter (sum of the capacity factor and grid charging factor).

The observed values for these three metrics (Table 5) demonstrate increasing utilization of the PV-BES inverter with increasing ILR. The higher capacity factor with increasing ILR is a result of the recovery of otherwise-clipped (or spilled) energy, which is recovered by the DC-coupled battery and dispatched later, thus increasing the overall energy output. The same drivers contribute to an increasing utilization factor with increasing ILR, but this increase is partially offset by corresponding (and expected) decreases in the grid charging factor. In particular, the grid charging factor declines from $8.1 \%$ with ILR $=1.3$ to $2.1 \%$ with ILR $=2.0$, reflecting the reduction in grid charging when the PV-BES hybrid has excess DC energy available from the oversized PV component. The modest amount of grid charging with the highest ILRs reflects periods of low irradiance.

Table 5. Utilization Metrics for the DC-Coupled Hybrid-Inverter

\begin{tabular}{cccc}
\hline ILR & $\begin{array}{c}\text { Capacity } \\
\text { Factor (\%) }\end{array}$ & $\begin{array}{c}\text { Grid Charging } \\
\text { Factor (\%) }\end{array}$ & $\begin{array}{c}\text { Utilization } \\
\text { Factor (\%) }\end{array}$ \\
\hline 1.3 & 41.3 & 8.1 & 49.4 \\
1.4 & 43.3 & 7.5 & 50.8 \\
1.5 & 45.2 & 6.8 & 51.9 \\
1.6 & 46.7 & 5.7 & 52.4 \\
1.7 & 48.1 & 4.7 & 52.8 \\
1.8 & 49.1 & 3.6 & 52.7 \\
1.9 & 50.1 & 2.8 & 52.8 \\
2.0 & 50.8 & 2.1 & 52.9 \\
\hline
\end{tabular}

Figure 7 represents the destination of all PV DC energy collected over the course of the year for all the simulated PV-BES hybrids as a function of ILR. In general, PV DC energy can be categorized as being: 
- Utilized (for direct electricity generation [brown] or charging the battery [yellow])

- Unutilized (due to losses associated with the various conversions [red] or spilled [grey]).

In addition to demonstrating the growing availability of PV DC energy with increasing ILR, the breakdown of utilized PV DC energy in Figure 7 indicates that most is sent directly to the grid and $15 \%-25 \%$ is used to charge the local battery.

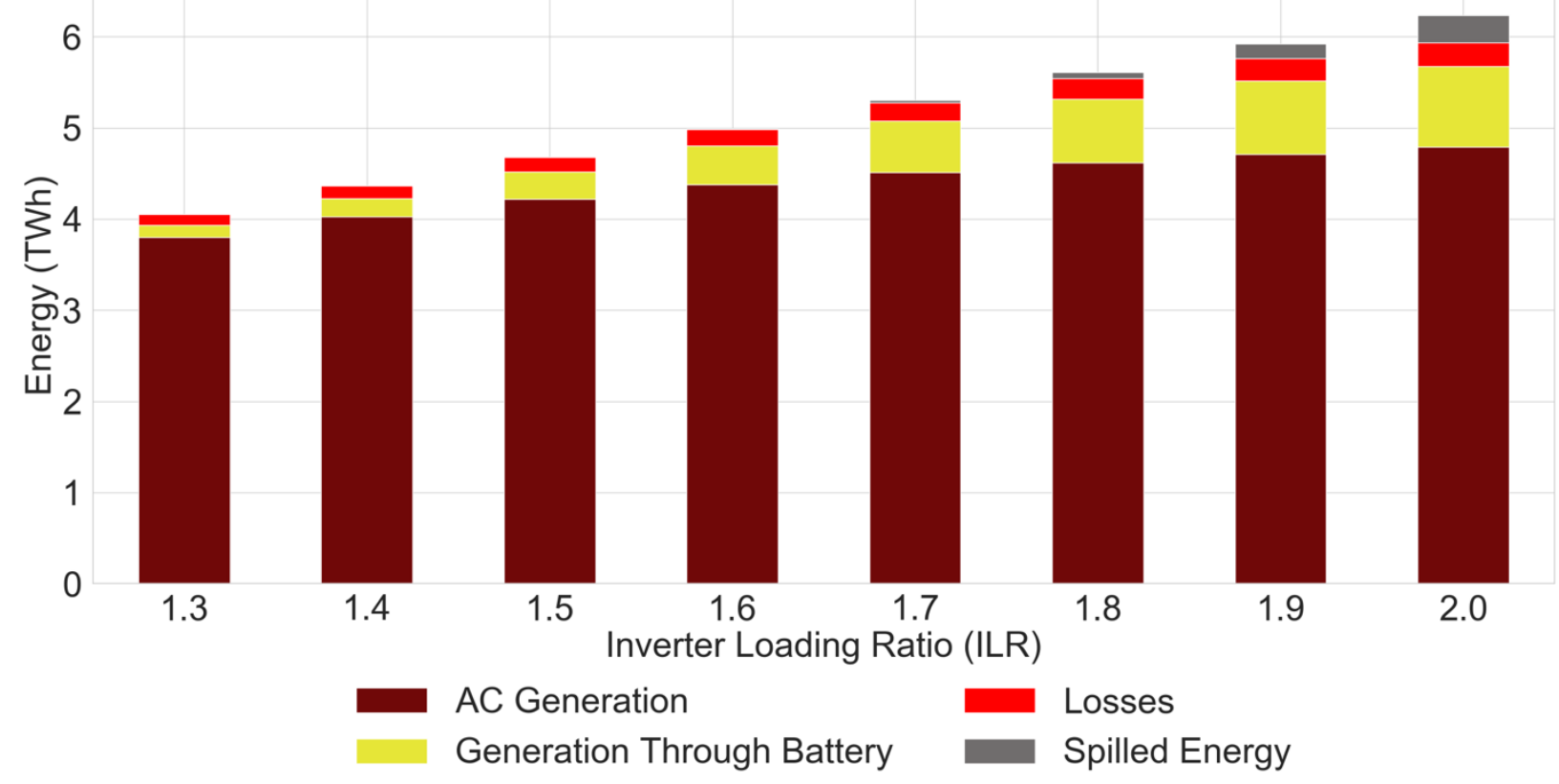

Figure 7. Destination of PV DC energy collected as a function of ILR for all DC-coupled PV-BES hybrids in this demonstration

The stacked sum of these bars represents the total DC energy available for each ILR.

The DC energy that cannot be utilized for either electricity generation or battery charging is spilled (wasted), which becomes more common in the higher ILR (1.8 and above) systems (Figure 8). For our assumed PV-BES setup, most of the spilled energy occurs because of insufficient battery energy capacity (for recovering the clipped PV energy). However, the converter limit is reached when the clipped DC power is greater than the converter capacity, which is observed during a few intervals in the PV-BES hybrids with ILR=2.0. A significant share of inverter losses come from PV generation, and from battery discharge as ILR increases. The increase in converter and battery losses is also observed as the we reach higher ILR. 


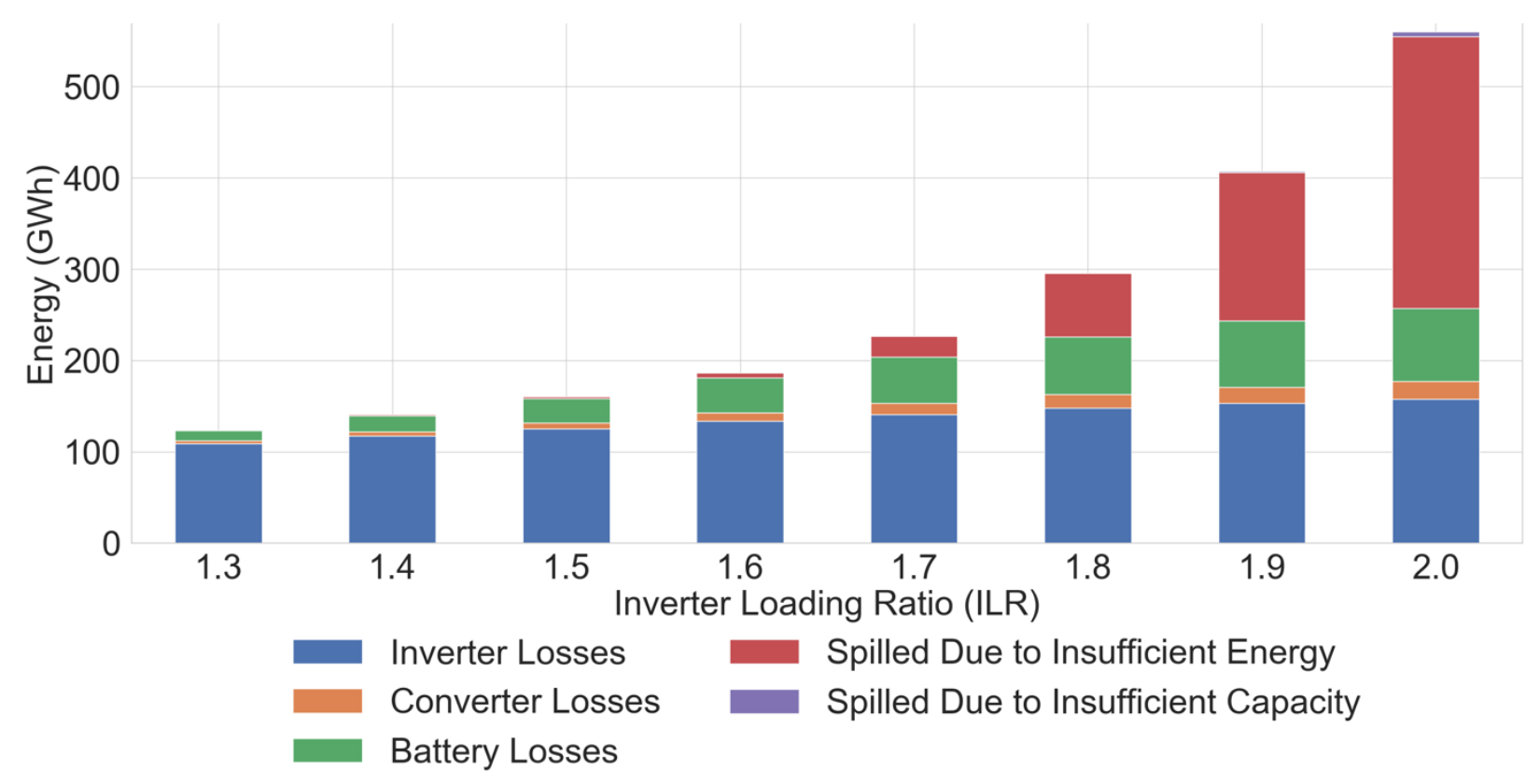

Figure 8. The distribution of the unutilized PV DC energy due to losses and spillage

Finally, due to the increasing availability of DC energy with higher ILRs, the production cost of the system will decline as the utilization of more otherwise-clipped, zero-cost DC energy displaces the need for higher-cost generation. Figure 9 illustrates this result by showing how the annual production costs for the entire LADWP system (green bars) decline as the assumed ILR of the PV-BES units increases.

Figure 9 also shows the incremental value of the additional PV energy produced with higher ILRs (blue bars), which is evaluated as the ratio of the change in production cost to the change in PV utilization, using the results for ILR $=1.3$ as the baseline:

additional $P V$ value $_{i}=\frac{P C_{i}-P C_{1.3}}{\text { net } P V_{i}-\text { net } P V_{1.3}}, \forall i=1.4,1.5 \ldots 2.0$

where $P C_{i}$ corresponds to the annual production cost of the system for ILR=i, and the $n e t P V_{i}$ is the aggregated PV energy utilized in a year for the system with ILR= $i$ (including PV DC energy that is utilized for generation and charging the battery. This shows a general downward trend as a greater fraction of stored energy is discharged during periods of lower value. For ILRs of 1.8 and above, the additional PV value plateaus as the amount of spilled energy grows, due to limitations imposed by the assumed battery size. 


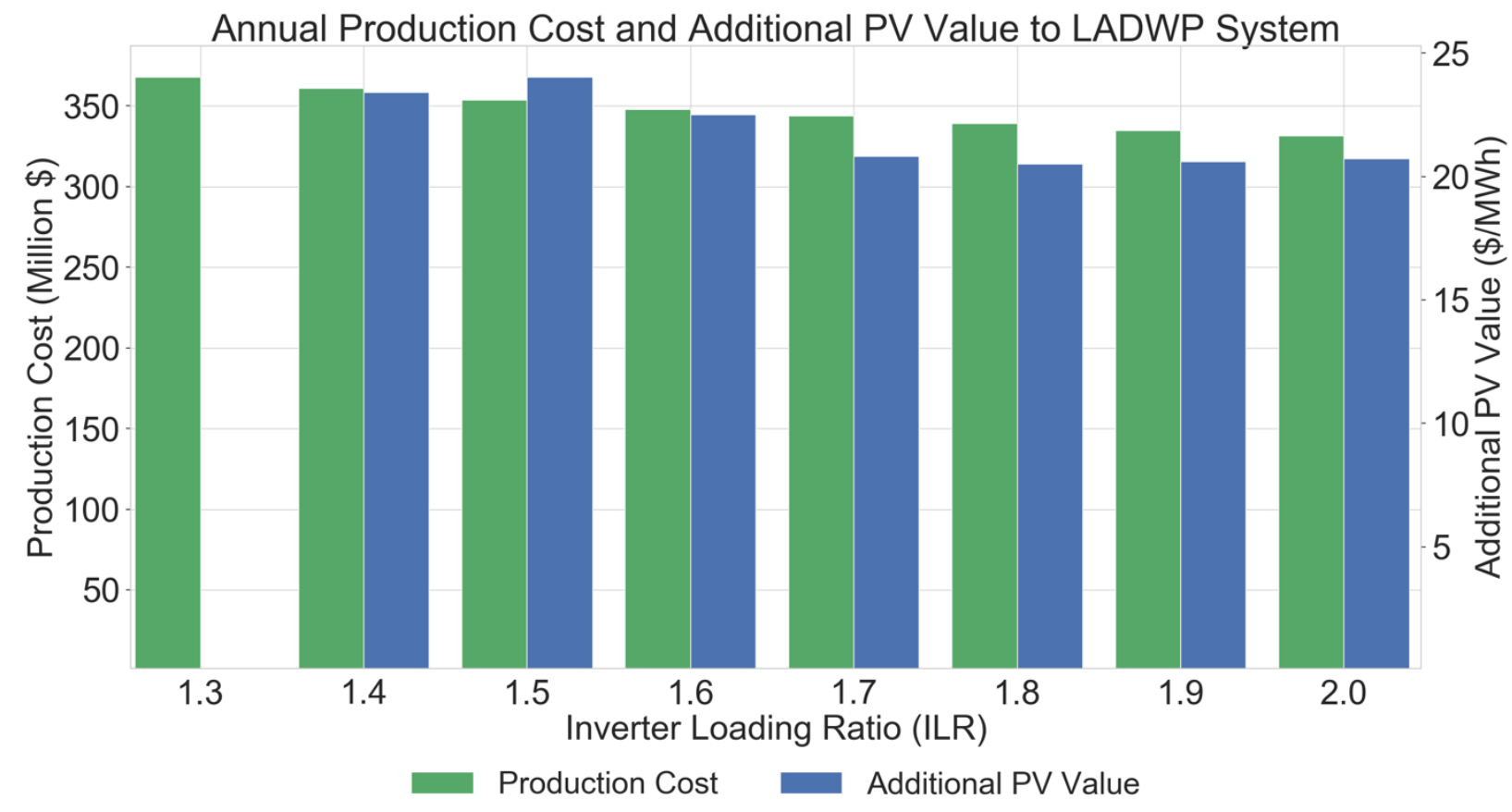

Figure 9. Annual production cost of the LADWP for each ILR and the additional value adding PV brings to the system with respect to ILR=1.3 


\section{Conclusions and Future Work}

In this paper, we present a method to represent a DC-coupled PV-BES in a commercial PCM, with PLEXOS as the demonstrated test case. This method can be reproduced in any other PCM software, and it is a critical step toward being able to evaluate the system benefits that DCcoupled PV-BES can provide, particularly if it is deployed with higher ILRs in the future. The proposed model in PLEXOS includes an explicit representation of both sides of the DC-coupled PV-BES hybrid's inverter (i.e., separate DC and AC "sides"), which is essential for both representing the synergies of DC-coupled PV-BES hybrids and validating the model. This model is developed such that the size of each component (PV, battery, converter, and inverter) of a DCcoupled PV-BES can be varied and analyzed.

To demonstrate our model, we implemented hypothetical DC-coupled PV-BES hybrids on the LADWP test system and evaluated the operational behavior and system costs across one year (2020). This demonstration revealed that each possible flow among all the components of the DC-coupled PV-BES can be observed, with select days combining multiple modes of operation that demonstrate the constraints and efficiencies. In addition to observing specific days, an aggregated analysis of the model demonstrated the capabilities of a PV-BES. The growing availability of PV DC energy with increasing ILR resulted in (a) an increase in the utilization of the inverter (e.g., capacity factor), (b) a reduction in grid charging (in favor of charging from the local PV, which is more-efficient and zero-cost), and (c) a decrease in system-wide production cost.

Overall, we believe this model will serve the research community with a comprehensive approach to representing DC-coupled PV-BES in a PCM in order to evaluate the system-level benefits of such systems. Potential valuable future work includes the following.

- This work demonstrated the operational behavior of DC-coupled PV-BES, whose contributions to the grid mix inherently reduce system-wide production cost (particularly for higher ILR systems). Translating this reduced production cost into economic benefit requires comparing the production cost savings against the corresponding PV-BES investment costs, which are not considered in this initial demonstration.

- To enable the more detailed treatment of ILR variations, this work explored a single storage technology with fixed operational characteristics (e.g., round-trip efficiency) and sizing. Future analysis with this model architecture could explore the effect of increasing battery size (energy and capacity), including interactions with different ILRs (for the coupled PV component) and system-wide production costs. Also, a more detailed representation of when battery-related losses occur (e.g., attributing specific shares of the round-trip efficiency to the charging and discharging periods) might improve the precision of this modeling. Finally, different storage and charging technologies could also be evaluated to understand the ideal configurations and technology combinations for various power system applications (e.g., regulation), accounting for the potential for charging speed restrictions.

- This work explored interactions of nodal energy prices and the DC-coupled PV-BES operations. Additional model development is needed to enable an evaluation of the capacity and reserve capabilities of this technology, within the context of the price dynamics that are captured in a PCM. 
- The present PCM modeling demonstrates the value that DC-coupled PV-BES could provide to a vertically integrated utility. Estimating the revenue associated with such systems requires combining multiple model techniques, such as estimating revenues from PCM results or employing a combination of PCM-generated prices with price-taker modeling of the corresponding DC-coupled PV-BES configuration (Schleifer et al. 2021). Such an evaluation would help inform investment decisions for potential PV-BES plant developers and owners in competitive market regions. 


\section{References}

Bullich-Massagué, Eduard, Francisco-Javier Cifuentes-García, Ignacio Glenny-Crende, Marc Cheah-Mañé, Mònica Aragüés-Peñalba, Francisco Díaz-González, and Oriol GomisBellmunt. 2020. "A Review of Energy Storage Technologies for Large Scale Photovoltaic Power Plants.” Applied Energy 274 (September): 115213. https://doi.org/10.1016/j.apenergy.2020.115213.

Chen, Y., A. Q. Huang, and X. Yu. 2013. "A High Step-Up Three-Port DC-DC Converter for Stand-Alone PV/Battery Power Systems." IEEE Transactions on Power Electronics 28 (11): 5049-62. https://doi.org/10.1109/TPEL.2013.2242491.

Cochran, Jaquelin, and Paul Denholm. 2021. "The Los Angeles 100\% Renewable Energy Study.” NREL/TP-6A20-79444. https://maps.nrel.gov/la100/.

Cole, Wesley, Sean Corcoran, Nathaniel Gates, Daniel Mai, Trieu, and Paritosh Das. 2020. "2020 Standard Scenarios Report: A U.S. Electricity Sector Outlook." NREL/TP-6A2077442. Golden, CO: National Renewable Energy Laboratory. https://www.nrel.gov/docs/fy21osti/77442.pdf.

DiOrio, Nicholas, Paul Denholm, and William B. Hobbs. 2020. "A Model for Evaluating the Configuration and Dispatch of PV plus Battery Power Plants." Applied Energy 262 (March): 114465. https://doi.org/10.1016/j.apenergy.2019.114465.

EIA. 2020. "Annual Energy Outlook 2020.” Washington, D.C.: U.S. DOE Energy Information Administration. https://www.eia.gov/outlooks/aeo/pdf/AEO2020\%20Full\%20Report.pdf.

Elgqvist, Emma, Kate Anderson, and Edward Settle. 2018. "Federal Tax Incentives for Energy Storage Systems." National Renewable Energy Laboratory. https://www.nrel.gov/docs/fy18osti/70384.pdf.

Freeman, Janine M., Nicholas A. DiOrio, Nathan J. Blair, Ty W. Neises, Michael J. Wagner, Paul Gilman, and Steven Janzou. 2018. "System Advisor Model (SAM) General Description (Version 2017.9.5)." NREL/TP-6A20-70414. National Renewable Energy Lab. (NREL), Golden, CO (United States). https://doi.org/10.2172/1440404.

$\mathrm{Fu}$, Ran, Timothy Remo, and Robert Margolis. 2018. "Evaluating the Cost Benefits of U.S. Utility-Scale Photovoltaics Plus Energy Storage Systems." In 2018 IEEE 7th World Conference on Photovoltaic Energy Conversion (WCPEC) (A Joint Conference of 45th IEEE PVSC, 28th PVSEC 34th EU PVSEC), 1-4. https://doi.org/10.1109/PVSC.2018.8547852.

Gilman, Paul, Nathan Blair, M. Mehos, Craig Christensen, Steve Janzou, and Chris Cameron. 2008. "Solar Advisor Model User Guide for Version 2.0," January. https://doi.org/10.2172/937349.

Good, Jeremy, and Jeremiah Johnson. 2016. "Impact of Inverter Loading Ratio on Solar Photovoltaic System Performance." Applied Energy 177 (September): 475-86. https://doi.org/10.1016/j.apenergy.2016.05.134.

Gorman, Will, Andrew Mills, Mark Bolinger, Ryan Wiser, Nikita G. Singhal, Erik Ela, and Eric O'Shaughnessy. 2020. "Motivations and Options for Deploying Hybrid Generator-plusBattery Projects within the Bulk Power System.” The Electricity Journal 33 (5): 106739. https://doi.org/10.1016/j.tej.2020.106739.

Hirth, Lion. 2013. "The Market Value of Variable Renewables." Energy Economics 38: 218-36. http://dx.doi.org/10.1016/j.eneco.2013.02.004. 
. 2015. "The Optimal Share of Variable Renewables:How the Variability of Wind and Solar Power Affects TheirWelfare-Optimal Deployment." The Energy Journal 36 (1): 127-62. http://dx.doi.org/10.5547/01956574.36.1.5.

Hledik, Ryan, Roger Leuken, Judy Chang, Hannes Pfeifenberger, Jesse Cohen, and John Imon Pedtke. 2019. "Solar-Plus-Storage: The Future Market for Hybrid Resource." December. https://brattlefiles.blob.core.windows.net/files/17741_solar_plus_storage_economics_final.pdf.

$\mathrm{Hu}$, Jiefeng, Yinliang Xu, Ka Wai Cheng, and Josep M. Guerrero. 2018. “A Model Predictive Control Strategy of PV-Battery Microgrid under Variable Power Generations and Load Conditions." Applied Energy 221 (July): 195-203. https://doi.org/10.1016/j.apenergy.2018.03.085.

Jorgenson, Jennie, Paul Denholm, Mark Mehos, and Craig Turchi. 2013. "Estimating the Performance and Economic Value of Multiple Concentrating Solar Power Technologies in a Production Cost Model." NREL/TP-6A20-58645. National Renewable Energy Lab. (NREL), Golden, CO (United States). https://doi.org/10.2172/1260920.

Jorgenson, Jennie, Matthew O'Connell, Paul Denholm, Janna Martinek, and Mark Mehos. 2018. "A Guide to Implementing Concentrating Solar Power in Production Cost Models." NREL/TP-6A20-68527. National Renewable Energy Lab. (NREL), Golden, CO (United States). https://www.nrel.gov/docs/fy19osti/68527.pdf.

King, David, Sigifredo Gonzalez, Gary Galbraith, and William Boyson. 2007. "Performance Model for Grid-Connected Photovoltaic Inverters." SAND2007-5036. Sandia National Laboratory. https://energy.sandia.gov/wp-content/gallery/uploads/Performance-Modelfor-Grid-Connected-Photovoltaic-Inverters.pdf.

Mai, Trieu, Wesley Cole, and Andrew Reimers. 2019. "Setting Cost Targets for Zero-Emission Electricity Generation Technologies.” Applied Energy 250 (September): 582-92. https://doi.org/10.1016/j.apenergy.2019.05.001.

Martinek, Janna, Jennie Jorgenson, Mark Mehos, and Paul Denholm. 2018. “A Comparison of Price-Taker and Production Cost Models for Determining System Value, Revenue, and Scheduling of Concentrating Solar Power Plants.” Applied Energy 231 (December): 85465. https://doi.org/10.1016/j.apenergy.2018.09.136.

Martins Deschamps, Eduardo, and Ricardo Rüther. 2019. "Optimization of Inverter Loading Ratio for Grid Connected Photovoltaic Systems.” Solar Energy 179 (February): 106-18. https://doi.org/10.1016/j.solener.2018.12.051.

Mehos, M., J. Jorgenson, P. Denholm, and C. Turchi. 2015. "An Assessment of the Net Value of CSP Systems Integrated with Thermal Energy Storage.” Energy Procedia, International Conference on Concentrating Solar Power and Chemical Energy Systems, SolarPACES 2014, 69 (May): 2060-71. https://doi.org/10.1016/j.egypro.2015.03.219.

Mills, Andrew, and Pía Rodriguez. 2020. "A Simple and Fast Algorithm for Estimating the Capacity Credit of Solar and Storage." Energy 210. https://doi.org/10.1016/j.energy.2020.118587.

Mills, Andrew, and Ryan Wiser. 2012. "Changes in the Economic Value of Variable Generation at High Penetration Levels: A Pilot Case Study of California." LBNL-5445E. Ernest Orlando Lawrence Berkeley National Laboratory. https://emp.lbl.gov/sites/all/files/lbnl5445e.pdf.

Miñambres-Marcos, Víctor Manuel, Miguel Ángel Guerrero-Martínez, Fermín BarreroGonzález, and María Isabel Milanés-Montero. 2017. “A Grid Connected Photovoltaic 
Inverter with Battery-Supercapacitor Hybrid Energy Storage.” Sensors 17 (8): 1856. https://doi.org/10.3390/s17081856.

Mongird, Kendall, Vilayanur Viswanathan, Jan Alam, Charlie Vartanian, Vincent Sprenkle, and Richard Baxter. 2020. "2020 Grid Energy Storage Technology Cost and Performance Assessment." DOE/PA-0204. U.S. Department of Energy. https://www.pnnl.gov/sites/default/files/media/file/Final\%20\%20ESGC\%20Cost\%20Performance\%20Report\%2012-11-2020.pdf.

Schimpe, Michael, Maik Naumann, Nam Truong, Holger C. Hesse, Shriram Santhanagopalan, Aron Saxon, and Andreas Jossen. 2018. "Energy Efficiency Evaluation of a Stationary Lithium-Ion Battery Container Storage System via Electro-Thermal Modeling and Detailed Component Analysis." Applied Energy 210 (January): 211-29. https://doi.org/10.1016/j.apenergy.2017.10.129.

Schleifer, Anna H., Caitlin A. Murphy, Wesley J. Cole, and Paul L. Denholm. 2021. "The Evolving Energy and Capacity Values of Utilierty-Scale PV-plus-Battery Hybrid System Architectures.” Advances in Applied Energy, March, 100015. https://doi.org/10.1016/j.adapen.2021.100015.

Wang, G., M. Ciobotaru, and V. G. Agelidis. 2014. "Power Smoothing of Large Solar PV Plant Using Hybrid Energy Storage.” IEEE Transactions on Sustainable Energy 5 (3): 834-42. https://doi.org/10.1109/TSTE.2014.2305433.

Wiser, Ryan, Mark Bolinger, Will Gorman, Joe Rand, Seongeun Jeong, Joachim Seel, Cody Warner, and Ben Paulos. 2020. "Hybrid Power Plants: Status of Installed and Proposed Projects.” 34197. Lawrence Berkeley National Lab. (LBNL), Berkeley, CA (United States). https://emp.lbl.gov/publications/hybrid-power-plants-status-installed.

Wiser, Ryan, Andrew Mills, Joachim Seel, Todd Levin, and Audun Botterud. 2017. "Impacts of Variable Renewable Energy on Bulk Power System Assets, Pricing, and Costs." Lawrence Berkely National Laboratory and Argonne National Laboratory. https://emp.lbl.gov/sites/default/files/lbnl_anl_impacts_of_variable_renewable_energy_fi nal.pdf. 


\section{Appendix: Transmission-Line Inverter Topology}

This appendix presents an alternative to the model presented in Section 4 and explored throughout this report. In this alternative approach, a constrained transmission line represents the hybrid-inverter, as depicted in Figure A-1. Therefore, we refer to this approach as the transmission-line inverter topology.

The implementation starts with the addition of a new node to the system, which (a) represents the point of common connection of the PV object and battery object, and (b) enables an explicit representation of the DC-side on which the hybrid components are coupled. The inverter is replaced by a lossless transmission line, for which the line rating property is set to equal to the inverter rating $\left(P_{i n v}\right)$ and the line efficiency property is set to equal to the inverter efficiency $\left(\eta_{\text {inv }}\right)$. The PV is represented by a PLEXOS generator object with the rating property $\left(P_{P V}\right)$ pointing toward an external file containing the time-series PV-DC profile $\left(P_{D C}^{t}\right)$, which is defined by the hybrid's location and size.

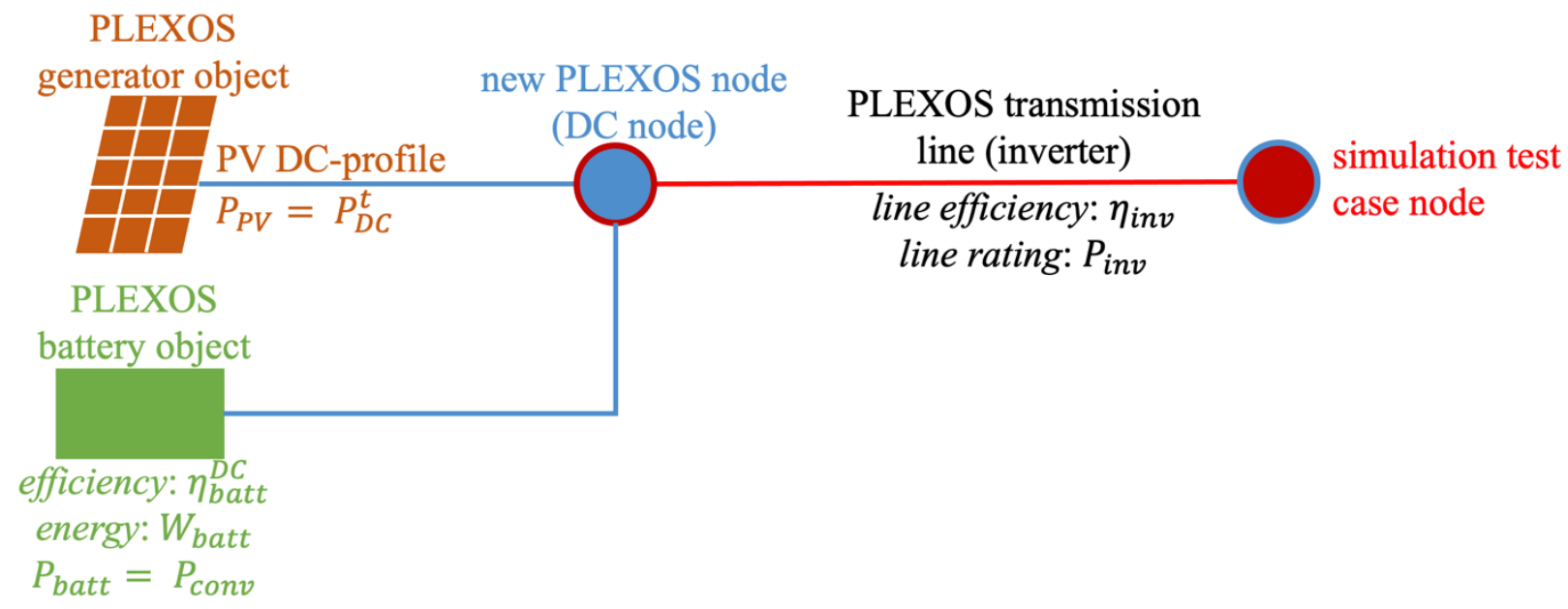

Figure A-1. PLEXOS implementation of DC-coupled PV-BES using a transmission lineinverter topology

In this approach, a transmission line represents the shared inverter in a DC-coupled PV-BES hybrid.

The battery object in PLEXOS includes an inherent representation of the battery inverter. When using this object in this model, we assume the inverter to be a DC-DC converter. The battery energy $\left(W_{\text {batt }}\right)$ will remain the same, and the rating property $\left(P_{\text {batt }}\right)$ will be equal to the rating of the converter $\left(P_{c o n v}\right)$. The efficiency of the battery $\left(\eta_{b a t t}^{D C}\right)$ is the product of the square of converter efficiency $\left(\eta_{\text {conv }}^{2}\right)$-which represents the round-trip efficiency (i.e., for charge and discharge cycle) of the battery-converter combination - and the battery internal efficiency $\left(\eta_{\text {batt }}\right)$, as described in Equation (14). The internal battery losses account for the losses that occur during the conversion from chemical to electrical energy (and vice-versa).

$$
\eta_{\text {batt }}^{D C}=\eta_{\text {batt }} \eta_{c o n v}^{2}
$$


Because the PLEXOS generator and battery objects generate AC power, a transmission line that links the new node (DC) and the system emulates the function of the shared inverter. The line parameters are set based on the inverter ratings. The line rating (flow limit) is set to equal to the inverter rating $\left(P_{\text {inv }}\right)$. The line efficiency property is set to equal to the weighted inverter efficiency $\left(\eta_{\text {inv }}\right)$. It must be noted that in PLEXOS, this is a dual property (flow and backflow), so the value must be set for both directions of flow.

Using this model for PCM simulations in PLEXOS requires some additional options to be enabled in order for it to function as intended:

- Line losses must be enforced so that the transmission line connecting the DC node to the system emulates an inverter.

- Line limits must be enforced so that the line rating represents the inverter limit.

- The rating file for the PV generator must belong to the DC-rating of the PV setup.

Although this is an issue that is specific to PLEXOS, some of the flows that include the converter cannot be monitored as the converter is considered as an internal component of the battery. Because of the added node and transmission line, the transmission-line inverter topology can increase the complexity of the problem, especially when a large number of PV-BES are added to the system. 